\title{
Polymeric nanoparticles and nanomicelles of hydroxychloroquine co-loaded with azithromycin potentiate anti-SARS-CoV-2 effect
}

\author{
Aline Oliveira da Siliva de Barros ${ }^{1}$ - Suyene Rocha Pinto ${ }^{1}$. Sara Rhaissa Rezende dos Reis ${ }^{1}$ Eduardo Ricci-Junior ${ }^{2}$. \\ Luciana Magalhães Rebelo Alencar ${ }^{3} \cdot$ Nancy Cristina Junqueira Bellei ${ }^{4} \cdot$ Luiz Ramos Mário Janini $^{5}$. \\ Juliana Terzi Maricato ${ }^{5} \cdot$ Daniela Santoro Rosa ${ }^{5} \cdot$ Ralph Santos-Oliveira ${ }^{1,6}$ (I)
}

Received: 15 June 2021 / Accepted: 27 November 2021 / Published online: 26 February 2022

(c) The Author(s), under exclusive licence to Islamic Azad University 2022

\begin{abstract}
The outbreak of coronavirus (COVID-19) has put the world in an unprecedented scenario. To reestablish the world routine as promote the effective treatment of this disease, the world is looking for new (and old) drug that can efficiently kill the virus. In this study, we have developed two nanosystems: polymeric nanoparticles and nanomicelles-based on hydroxychloroquine and azithromycin. The nanosystem was fully characterized by AFM and DLS techniques. Also, the nanosystems were radiolabeled with ${ }^{99 \mathrm{~m}} \mathrm{Tc}$ and pulmonary applied (installation) in vivo to evaluate the biological behavior. The toxicity of both nanosystem were evaluated in primary cells (FGH). Finally, both nanosystems were evaluated in vitro against the SARS-CoV-2. The results demonstrated that the methodology used to produce the nanomicelles and the nanoparticle was efficient, the characterization showed a nanoparticle with a spherical shape and a medium size of $390 \mathrm{~nm}$ and a nanomicelle also with a spherical shape and a medium size of $602 \mathrm{~nm}$. The nanomicelles were more efficient $(\sim 70 \%)$ against SARS-CoV-2 than the nanoparticles. The radiolabeling process with ${ }^{99 \mathrm{~m}} \mathrm{Tc}$ was efficient $(>95 \%)$ in both nanosystems and the pulmonary application demonstrated to be a viable route for both nanosystems with a local retention time of approximately, $24 \mathrm{~h}$. None of the nanosystems showed cytotoxic effect on FGH cells, even in high doses, corroborating the safety of both nanosystems. Thus, claiming the benefits of the nanotechnology, especially with regard the reduced adverse we believe that the use of nanosystems for COVID-19 treatment can be an optimized choice.
\end{abstract}

Ralph Santos-Oliveira

roliveira@ien.gov.br

1 Laboratory of Nanoradiopharmacy and Synthesis of New Radiopharmaceuticals, Nuclear Engineering Institute, Brazilian Nuclear Energy Commission, Rio de Janeiro, Brazil

2 Galenical Development Laboratory, College of Pharmacy, Federal University of Rio de Janeiro, Rio de Janeiro, Brazil
3 Department of Physics, Federal University of Maranhão, Maranhão, Brazil

4 Department of Medicine, Federal University of São Paulo, São Paulo, Brazil

5 Department of Microbiology, Immunology and Parasitology, Federal University of São Paulo, São Paulo, Brazil

6 Laboratory of Radiopharmacy and Nanoradiopharmaceuticals, Zona Oeste State University, Rio de Janeiro, Brazil 


\section{Graphical abstract}

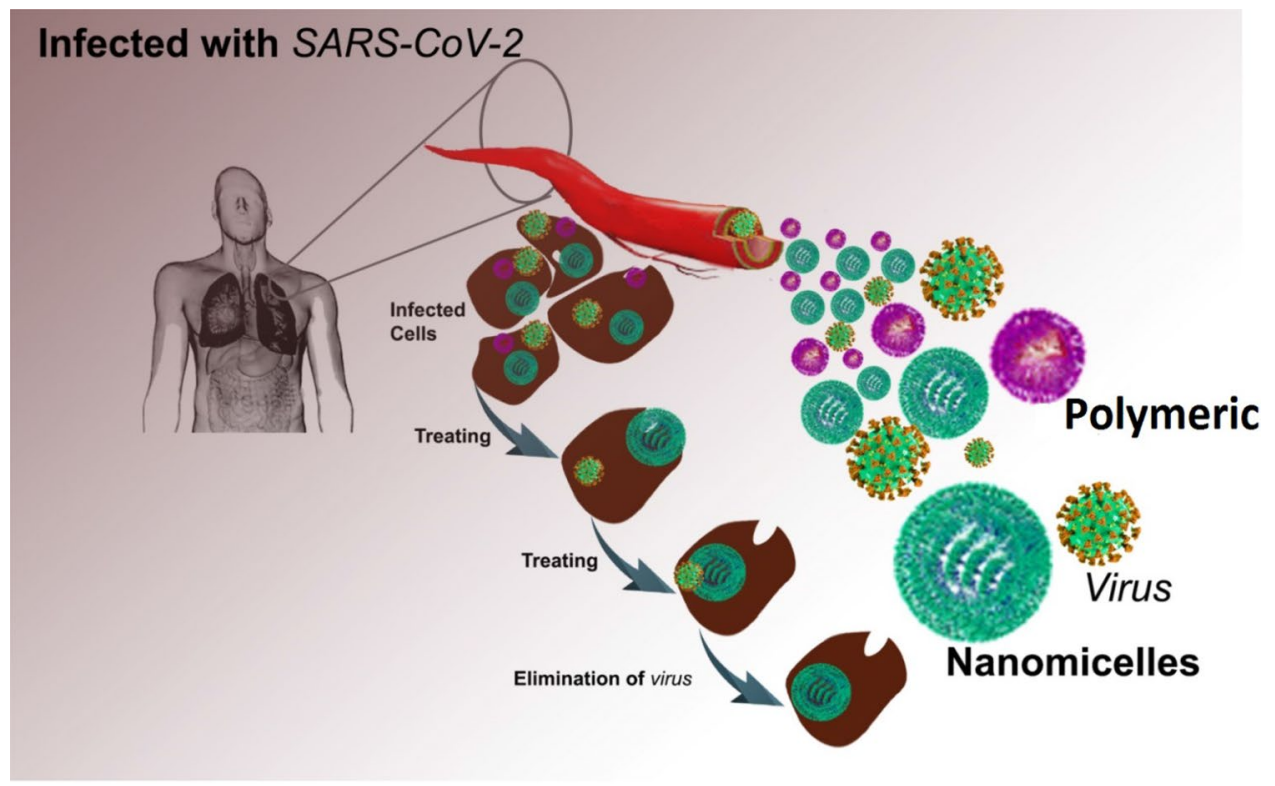

Keywords Drug · Nanotechnology · COVID-19 - SARS-CoV-2 $\cdot$ Virus · Treatment

\section{Introduction}

Coronaviruses (CoVs) are known to mainly cause respiratory and gastrointestinal tract infections. Six subtypes of CoVs have been identified to infect humans: SARS-CoV (severe acute respiratory syndrome coronavirus), MERS-CoV (Middle East respiratory syndrome coronavirus), $\mathrm{HCoV}-\mathrm{OC} 43$, HCoV-HKU1, HCoV-NL63, and HCoV-229E [1]. Late 2019, a novel human coronavirus (SARS-CoV-2) emerged in Wuhan city, China and rapidly spread worldwide causing a global outbreak [2]. The disease caused by SARS-CoV-2, COVID-19, is a highly transmissible and pathogenic coronavirus [3], which became a major global public health [4, 5]. The most common symptoms of SARS-CoV-2 infection are fever, dry cough, dyspnea, lymphopenia and fatigue [6-8] that can progress to severe illness leading to respiratory failure and acute respiratory distress syndrome (ARDS) [9, 10]. In general, $15 \%$ of the cases progress to severe illness [11] and, eventually, multiple organ failure [12]. Although COVID-19 has lower fatality rate than SARS and MERS, the overall deaths from COVID-19 is far outweigh. Most people are susceptible to the new virus since there are no preexisting immunity. Elderly [13] and individuals with comorbidities such as diabetes, hypertension, chronic obstructive lung disease and coronary heart disease are more prone to develop severe COVID-19 [8, 14]. Thus, it is of utmost importance to develop successful treatments to fight the pandemic. So far, several compounds have emerged as potential candidates to inhibit SARS-CoV-2 infection in vitro, and some of them have already entered clinical trials $[15,16]$. Among the compounds being tested are hydroxychloroquine (HCQ) and azithromycin (AZT) [17].

Hydroxychloroquine (HCQ) sulfate is a derivative of chloroquine (CQ) with a very similar chemical structure but much less toxic [18]. Previous studies demonstrated the ability of HCQ to inhibit SARS-CoV-2 in vitro [19] and also in COVID-19 patients [17].According to Ou et al. [20] the hydroxychloroquine efficiently blocks viral entry mediated by cathepsin L, but not by TMPRSS2, which corroborates the use associated with other drug. AZT was reported to inhibit the replication of Zika [21, 22] and Ebola viruses [23] and also prevent severe upper respiratory infections [24]. Also, as reported by Khezri et al. [25], azithromycin can inhibit viral load, viral replication, mainly due its immunomodulatory properties, which includes: (i) downregulation of cytokine production; (ii) maintenance of epithelial cell integrity and (iii) prevention lung fibrosis [26]. The association of HCQ and AZT in the treatment of COVID-19 patients presented a synergistic effect in reducing viral loads when compared to HCQ alone [17]. Recently a study from Arshad et al. [27] claimed that the use of HCQ plus AZT in positive COVID-19 patients is associated with reduction in mortality.

The use of nanosystems for the treatment of viruses may be a reliable form to increase the efficacy and reduce the toxicological effect of many antivirals in use $[28,29]$. Due 
to the molecular and atomically [30-33] properties of the nanosystems, a more facilitate delivery and uptake for the virus/or infected cells may be reached [34]. Also, the fact that nanosystems shows a large surface area [35-37], allowing a highly payload $[38,39]$ with specific antiviral drugs increasing the efficacy is a desired effect. The tunable surface charge $[40,41]$ which increases the cellular trafficking $[42,43]$, allowing the intracellular effect is also quite desirable. Nonetheless, is important to notice that nanosystem may be constructed to biomimetic several targets: cell, virus and bacteria, increasing the therapeutic effect. In contrast the highly target associated with maximum payload result in an increased efficacy with a reduced direct and acute adverse effects [44]. Osminkina et al. [45] have used porous silicon nanoparticles against virus infection.

In this study we designed, synthesized, characterized by dynamic light scattering (DLS) analysis and atomic force microscopy (AFM), and in vitro evaluated two nanosystems based on hydroxychloroquine associated with azithromycin (nanomicelles and nanoparticles) as a possible new strategy for the treatment of COVID-19. The pulmonary route has been also investigated in vivo by radiolabeling both nanosystem with ${ }^{99 \mathrm{~m}} \mathrm{Tc}$ and applying by installation direct in lungs. Finally, the safety aspect of both nanosystem has been evaluated by performing wound-healing assay in FGH cells.

\section{Materials and methods}

\section{Reagents}

Polylactic acid (PLA), Polyvinyl alcohol (PVA) Phosphate buffered saline (PBS), PBS/EDTA (10 nM) freshly prepared solution, Freund's complete adjuvant, Histopaque reagent, Pluronic F127, DMEM high glucose, bovine fetal serum, doxorubicin, poly-D-lysine, glucose, HEPES, calcium and magnesium were purchased from Sigma Aldrich (St. Louis, MO, USA). Hydroxychloroquine was purchased from Infinity pharma and azithromycin was purchased from Eurofarma.

\section{Production}

\section{Hydroxychloroquine nanomicelles}

The nanomicelles dispersion of Pluronic F127 at concentration of $10 \%(\mathrm{w} / \mathrm{w})$ was prepared. A mass of $200 \mathrm{mg}$ of hydroxychloroquine and $50 \mathrm{mg}$ of dehydrated azithromycin were weighed and added to $100 \mathrm{ml}$ of the micellar dispersion of Pluronic F127. The system was gently stirred using a magnetic bar (Magnetic Stirrer, IKA, C-MAG HS-7) for $5 \mathrm{~min}$ and then processed for $5 \mathrm{~min}$ using an ultrasonic processor (UP100H, Hielscher, Power: 60\%, Cycle: 1) under ice bath at $10{ }^{\circ} \mathrm{C}$. The dispersion of polymeric nanomicelles containing the drugs was stored in an amber flask for analysis of the size and polydispersity index.

\section{Hydroxychloroquine/azithromycin nanoparticles}

To the nanoparticle's preparation, an amount of $200 \mathrm{mg}$ of hydroxychloroquine and $5 \mathrm{mg}$ of azithromycin, $40 \%$ and $10 \%$ of the polymer mass, respectively, were solubilized in $1 \mathrm{~mL} 0.1 \mathrm{wt} \%$ PVA (Polyvinyl alcohol) (solution A). The PLA/PVA/hydroxychloroquine/azithromycin nanoparticles were prepared by double emulsion solvent evaporation. Thus, $1 \mathrm{~mL}$ of solution A was dripped into $3 \mathrm{~mL}$ of dichloromethane, where $50 \mathrm{mg}$ of PLA (Polylactic acid) (with a molar mass of $60,000 \mathrm{~g} / \mathrm{mol}$ ) were previously solubilized. The mixture was sonicated (UP100H, Hielscher, Teltow, Germany) for $1 \mathrm{~min}$ at $20 \%$ of amplitude to produce a water-in-oil $(\mathrm{O} / \mathrm{W})$ emulsion. This emulsion was emulsified again with $6 \mathrm{~mL}$ of PVA $1 \mathrm{wt} \%$ solution by sonication for 2 min (20\% of amplitude, UP100H, Hielscher, Teltow, Germany) to produce a $\mathrm{W} / \mathrm{O} / \mathrm{W}$ emulsion. Then dichloromethane was evaporated under reduced pressure during $1 \mathrm{~h}$ at $25{ }^{\circ} \mathrm{C}$ (Rotavapor R114, Buchi, Postfach, Switzerland). The nanoparticles were recovered by centrifugation $(20,000 \mathrm{rpm}$ for 20 min) Centrifugal Beckman Coulte TM J 25, Brea, California, USA) and washed twice with distilled water to remove the excess of PVA. Is important to point out that both polylactic acid (PLA) and Polyvinyl alcohol (PVA) are Food and Drug Administration approved polymers that have proven to be very versatile materials, with interesting properties such as biocompatibility and biodegradability $[46,47]$.

\section{Entrapment efficacy}

\section{Hydroxychloroquine (HCQ)}

The entrapment efficacy was determined by UV-spectrophotometry, using the methodology described by Singh et al. [48] and corroborated by Ferraz et al. [49]. Briefly, the $3 \mathrm{~mL}$ of $0.1 \mathrm{~N} \mathrm{HCl}$ (Sigma Aldrich) was added in $2 \mathrm{~mL}$ of nanoparticle supernatant. The spectroscopic determination was conducted at a wave light of $343 \mathrm{~nm}$.

\section{Azithromycin (AZT)}

The azithromycin entrapment efficacy was assessed by UV-Visible spectrophotometer. Briefly, $3 \mathrm{~mL}$ of $0.1 \mathrm{~N} \mathrm{HCL}$ (Sigma Aldrich) was added to $2 \mathrm{~mL}$ of nanoparticles supernatant, forming the solution A. Then, $1 \mathrm{~mL}$ of solution A was diluted with phosphate buffer (pH 6.8) up to $10 \mathrm{~mL}$. Then the final solution was analyzed by UV-spectrophotometry using wave light of $208 \mathrm{~nm}$ [50-52]. 


\section{Characterization}

\section{Average size determination by dynamic light scattering and zeta potential}

The size distribution, mean size, and polydispersity index (PDI) of both nanosystem were determined by dynamic light scattering (DLS) using the equipment Zetasizer Nano ZS (Malvern Instruments, UK). Measurements were performed in triplicate at $25^{\circ} \mathrm{C}$ and the laser incidence angle in relation to the sample was $173^{\circ}$ using a $12 \mathrm{~mm}^{2}$ quartz cuvette. The mean \pm standard deviation (SD) was assessed. The zeta potential from each nanosystem has been performed using a Litesizer 500 (Anton Paar, Germany). Measurements were performed at $20^{\circ} \mathrm{C}$ and the laser incidence angle in relation to sample was $15^{\circ}$, using an Omega shaped cuvette. All data is a mean of 1000 runs.

\section{Atomic force microscopy}

An AFM (Multimode 8 microscope (Bruker, Santa Barbara, CA) was used to measure topography, phase and mechanical properties of polymeric nanoparticles and polymeric films containing micelles. Samples are measured in both quantitative nanomechanics (QNM) and intermittent (Tapping) modes of operation. In tapping mode (phase image), we used rectangular silicon cantilevers (TESP7, Bruker) with a nominal spring constant of $42 \mathrm{~N} / \mathrm{m}$. In QNM mode, (topography, Young's Modulus maps, adhesion maps and energy dissipation maps) we used V shaped cantilevers (SCANASYSTAIR, Bruker) with a nominal spring constant of $0.4 \mathrm{~N} / \mathrm{m}$. All images were acquired at room temperature.
To analyze the elastic components and the energy dissipation due to the viscous forces of the polymeric film containing micelles, approximately 196,000 force curves were obtained in each $30 \mu \mathrm{m}$ map in three different regions of the film with 4 different indentation frequencies: $2 \mathrm{kHz}, 1 \mathrm{kHz}$, $0.5 \mathrm{kHz}$ and $0.25 \mathrm{kHz}$. The elasticity and energy dissipation due to the viscosity of the sample were analyzed with the frequency variation.

The Young's Modulus, $E$, and the logarithm of the elastic modulus $(\log E)$ is obtained by fitting the retract curve (Fig. 1 red dotted line) using the Derjaguin, Muller, Toropov (DMT) model [53] given by Eq. 1

$F_{\text {tip }}=\frac{4}{3} E \sqrt{R d^{3}}+F_{\text {adh }}$,

where $F_{\text {tip }}$ is the force on the tip, $F_{\text {adh }}$ is the adhesion force, $\mathrm{R}$ is the tip end radius and $\mathrm{d}$ is the tip-sample separation.

For viscous samples, the response to the cantilever force is composed of an elastic and a viscous component, such that the work done by the cantilever is partially lost by internal friction, generating a hysteresis in the approach/retraction cycle (Fig. 1). Energy Dissipation (W) is given by the force times the velocity integrated over one period of the vibration as demonstrated in Eq. 2:

$W=\int_{0}^{T} \vec{F} \cdot \vec{v} \mathrm{~d} t=\int \vec{F} \cdot \mathrm{d} Z$,

where $F$ is the interaction force vector and $\mathrm{d} Z$ is the displacement vector. Pure elastic deformation has no hysteresis, which corresponds to very low dissipation.
Fig. 1 Schematics of a typical AFM deflection-separation curve, exhibiting hysteresis between approach and retract curves, and adhesiveness. The fitting of these curves between a given interval of deflection with DMT model provides an estimate of the sample elasticity moduli E. From the hysteresis, we employed the method described below to determine the dissipation of energy due the viscosity

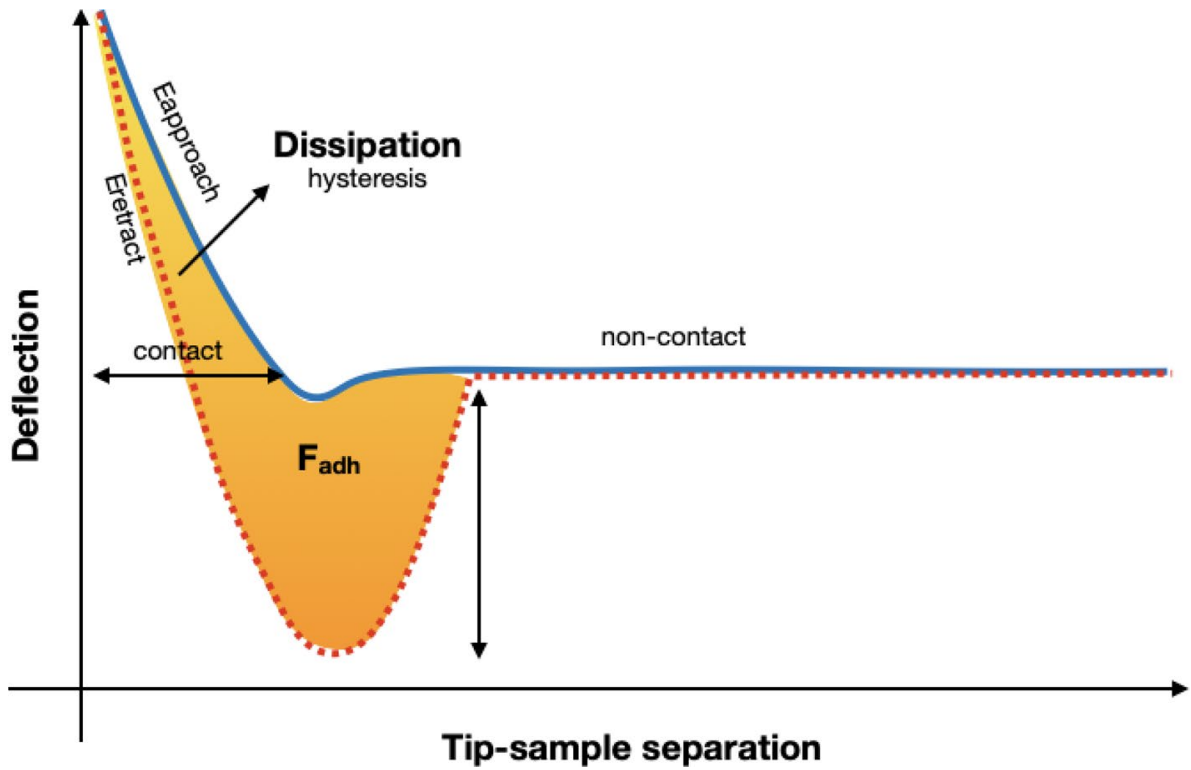




\section{Raman spectroscopy}

The Raman spectra were obtained using a Triple Raman spectrometer (model T64000, Horiba). The instrument was equipped with a confocal accessory and a liquid-N2-cooled charge-coupled device (CCD) detector. For excitation, a green $532.0 \mathrm{~nm}$ line from a solid-state laser (LAS-532-100HREV) operating at $14 \mathrm{~mW}$ was employed. The light was focused on the sample using an Olympus microscopy with a MPLN $100 \times$ objective lens. The spot of the scattered light was limited by the confocal accessory. The spectra were acquired in two ways: (i) at different points in the surface of the samples and (ii) by varying the position along the vertical direction centered on a particle.

\section{In vitro assay}

\section{Cell culture}

Human gingival fibroblast (FGH) cell lines were obtained from Cell Bank of Rio de Janeiro, Brazil (0190). The cells were maintained in DMEM/F12 medium, supplemented with 10\% FBS, NaHCO3 (3.7 g/L), HEPES (5.2 g/L), penicillin $(0.5 \mathrm{U} / \mathrm{mL})$ and streptomycin $(0.5 \mathrm{mg} / \mathrm{mL})$. Cells were incubated at $37{ }^{\circ} \mathrm{C}$ in a humidified atmosphere of $5 \% \mathrm{CO}_{2}$. Cells were grown to confluence in $75 \mathrm{~cm}^{2}$ culture flasks and were detached by brief treatment with trypsin $(0.1 \%)$ /EDTA (0.01\%) [54].

\section{Proliferation assay}

FGH cells $\left(5 \times 10^{3}\right.$ cells/well) were seeded and allowed to attach for $24 \mathrm{~h}$. These cells were cultured in medium with $10 \%$ FBS (untreated) or in medium containing nanosystems or the drug (HCQ) in different concentrations ( $25 \mu \mathrm{g} /$ $\mathrm{mL}, 50 \mu \mathrm{g} / \mathrm{mL}$ and $100 \mu \mathrm{g} / \mathrm{mL}$ ). After $24 \mathrm{~h}$, the cells were washed, and the number of attached cells was determined using the MTT assay [54].

\section{Wound-healing assay}

FGH cells $\left(2 \times 10^{5}\right.$ cells $)$ were seeded in 24 -well plates and allowed to attach for $24 \mathrm{~h}$. Wounds were created in confluent cells using a pipette tip. Cells were cultured in medium with $10 \%$ FBS (untreated) or in medium containing nanosystems or with the drugs (HCQ) in different concentrations ( $25 \mu \mathrm{g}$ / $\mathrm{mL}, 50 \mu \mathrm{g} / \mathrm{mL}$ and $100 \mu \mathrm{g} / \mathrm{mL}$ ) for another $24 \mathrm{~h}$. The culture plates were incubated at $37{ }^{\circ} \mathrm{C}$. Wound closure (\%) was calculated using the equation: (wound closure $\%$ ) = average of ([gap area: $0 \mathrm{~h}]$-[gap area: $24 \mathrm{~h}]) /[$ gap area: $0 \mathrm{~h}]) \times 100$, where the area at time zero $(0 \mathrm{~h})$ and the area after incubation time $(24 \mathrm{~h})$ were used to calculate the wound closure percentage. Image $\mathbf{J}$ software was used to detect the edge end position.

\section{In vitro antiviral effects}

Vero E6 cells (ATCC, $\mathrm{n}^{\circ}$ 1586) were cultured in Minimum Eagle's medium (MEM; Gibco) supplemented with $10 \%$ FBS (Gibco) and plated at 100,000 cells/well in a 48 well plate at $37{ }^{\circ} \mathrm{C}$ with $5 \% \mathrm{CO}_{2}$ atmosphere. Twenty-four hours later, the supernatant was harvest and the cells were pre-treated for $1 \mathrm{~h}$ with $100 \mu \mathrm{L}$ of medium containing different concentrations of the nanosystems or with the drugs $(\mathrm{HCQ}+\mathrm{AZT})$ as control. After this period, the SARS-CoV-2 isolate (EPI_ISL_413016) at a MOI of 0.05 was added to allow infection for $2 \mathrm{~h}$. Then, the nanosystem-virus mixture was removed and the cells were washed twice with PBS and cultured in the presence of fresh medium for further $48 \mathrm{~h}$ at $37{ }^{\circ} \mathrm{C}$ with $5 \% \mathrm{CO}_{2}$ atmosphere. The virus yield in culture supernatants was quantified by RT-qPCR using specific primers and probe against $R d r p$ gene according to RT-qPCR 2019-nCoV (Institute Pasteur protocol) [55]. Briefly, total RNA was isolated using QIAamp ${ }^{\circledR}$ Viral RNA kit (Qiagen) and the reaction was performed using Hot Start Go Taq ${ }^{\circledR}$ mix (Promega) in a 7500 Real-Time PCR System (Applied Biosystems). A standard curve was generated using synthetic RNA, and after determining the number of viral RNA copies in each sample the graphs were generated using the GraphPad Prism 7 software.

\section{Pulmonary application: in vivo tissue deposition}

\section{Radiolabeling with ${ }^{99 m} \mathrm{Tc}$}

The labeling process was done using $150 \mu \mathrm{g}$ of both nanodrugs. Each one was incubated with stannous chloride $\left(\mathrm{SnCl}_{2}\right)$ solutions $(80 \mu \mathrm{L} / \mathrm{mL}$ ) (Sigma-Aldrich) for $20 \mathrm{~min}$ at room temperature. Then, to each solution has been added $100 \mu \mathrm{Ci}$ (approximately $300 \mu \mathrm{L}$ ) of technetium-99 $\mathrm{m}$ and got in touch for another $10 \mathrm{~min}$ to label their structures [56].

\section{Quality control of the labeling process with Tc-99 m}

To confirm the efficacy of the radiolabeling process, radio thin layer chromatography (RTLC) was done using Whatman paper $n^{\circ} 1$. In this regard, $2 \mu l$ of each radiolabeled nanoparticle: ${ }^{99 \mathrm{~m}} \mathrm{Tc}-\mathrm{PLA} / \mathrm{PVA} /$ hydroxychloroquine/azithromycin and ${ }^{99 \mathrm{~m}} \mathrm{Tc}$-hydroxychloroquine/azithromycin nanomicelle and acetone (Sigma-Aldrich) as mobile phase at times of 2 and 4 and $24 \mathrm{~h}$ were evaluated. The radioactivity of the strips was verified in a $\gamma$-counter (Perkin Elmer Wizard ${ }^{\circledR}$ 2470, Shelton, CT City, State). The RTLC was performed in triplicate for each time. 


\section{Pulmonary application}

A total of 18 male naïve rats (Wistar rats) (3 animals per group) were anesthetized with $4.5-5.0 \%$ sevoflurane in air for the non-invasive intratracheal instillation of $180 \mu \mathrm{L}$ in a final volume of $100 \mu \mathrm{L}$. The maneuver was done with the help of a vertical restrained device as previously reported by Haspeslagh et al. [57]. Animals were sacrificed in $2 \mathrm{~h}$, $4 \mathrm{~h}$ and $24 \mathrm{~h}$ post injection and their organs were removed weighted and the radiation analyzed by $\gamma$-counter (Perkin Elmer Wizard ${ }^{\circledR} 2470$, Shelton, CT City, State).

\section{Results}

\section{Production}

\section{Hydroxychloroquine/azithromycin nanomicelles}

The result showed that the methodology used to produce hydroxychloroquine co-loaded with azithromycin nanomicelles was efficient.

\section{Hydroxychloroquine/azithromycin nanoparticles}

The result showed that the methodology used to produce hydroxychloroquine co-loaded with azithromycin nanoparticles was efficient.

\section{Entrapment efficacy}

The entrapment efficacy showed that $72.3 \%$ of hydroxychloroquine and $69.6 \%$ of the azithromycin has been loaded in the polymeric nanoparticles. Our research work involves the encapsulation of hydroxychloroquine and azithromycin in nanomicelles (micellar dispersion). In the micellar dispersion, the polymeric surfactant (Pluronic F127) forms nanomicelles with hydrophobic nucleus that encapsulate the hydrophobic drugs. Micellar dispersions are kinetically stable and homogeneous. There is a technical limitation to separate the nanomicelles from aqueous external medium or dispersing medium. Therefore, we used the nanomicelle bulk, without any further processing and in this case was considered an entrapment efficiency of $100 \%$.

\section{Average size determination by dynamic light scattering and zeta potential: nanomicelle}

The average diameter of the hydroxychloroquine/azithromycin nanomicelle showed a mean size of $602 \mathrm{~nm}$ (Fig. 2) with a PDI value of 0.348 . The PDI value of the nanomicelle is very near of the limit of a monodispersive behavior PDI (0.3). However, for pharmaceutical purposes we assumed

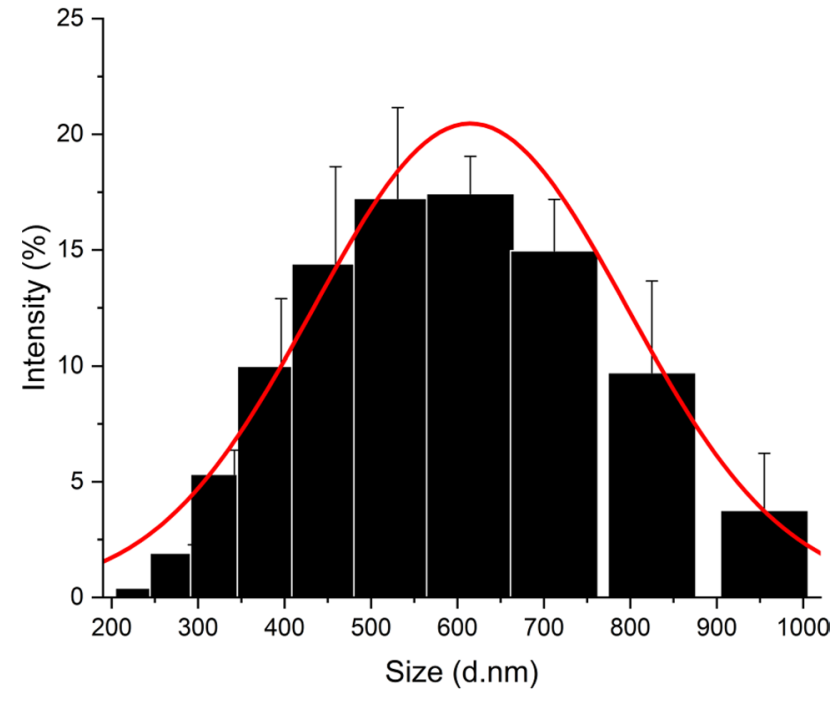

Fig. 2 DLS analysis of the nanomicelle, showing the mean size of $602 \mathrm{~nm}$

the limit of 0.3 and for that reason the nanomicelle did not show a monodispersive behavior. The zeta potential analysis showed a mean zeta potential of $0.1 \mathrm{mV}$, with a conductivity of $1.046 \mathrm{~S} / \mathrm{cm}$ and electrophoretic mobility of $0.0049 \mu \mathrm{m}$. $\mathrm{cm} / \mathrm{V} . \mathrm{s}$

\section{Atomic force microscopy: nanomicelle}

The topographic images of atomic force microscopy show the polymeric film containing micelles of circular structure as shown in Fig. 3. The size of the structures observed in the AFM is compatible with the DLS measurements. The micelle pointed by the green arrow in Fig. 3a has a diameter of $621 \mathrm{~nm}$ represented by the red dotted line. In the highresolution AFM topographic image, it is possible to observe different structures on the micelle. Motivated by these structures, we performed measurements of atomic force microscopy in phase mode. The AFM phase images monitor the phase lag of the cantilever oscillation over the sample and reflect its mechanical properties, mapping different materials in a sample. In Fig. $3 \mathrm{~b}$ it is possible to observe two very distinct phases on the nanomicelle: a lighter phase, formed by the polymer and a darker phase, inside the nanomicelle, formed by the drugs. Since the only three materials in the polymeric solution containing the loaded nanomicelles are the polymer and the drugs (hydroxychloroquine and azithromycin), these two-phase contrasts are compatible with a micellar encapsulation of the drugs.

Since the phase images only show different materials in a sample, due to the difference in their mechanical properties, however, it does not explain in detail about the mechanics of these materials, we perform quantitative nanomechanical 


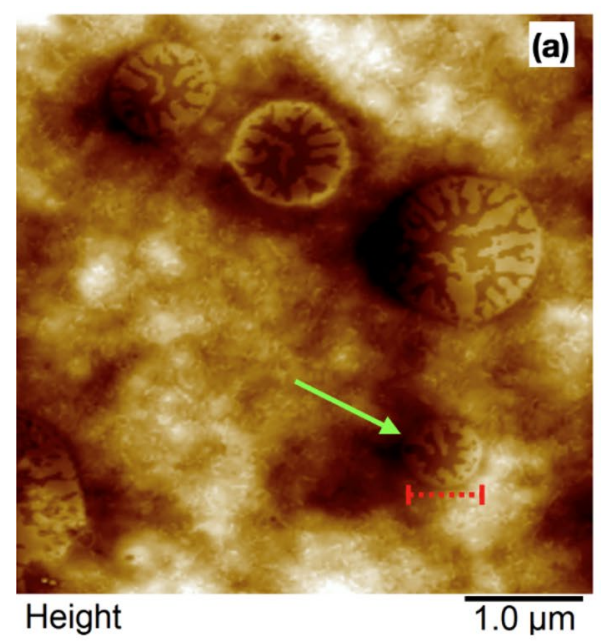

Fig. 3 AFM topographic image of Hydroxychloroquine/azithromycin polymeric nanomicelles emulsion. a Height image of the polymeric film containing the nanomicelles showing the circular shape of these micelles. The micelle pointed by the green arrow has $621 \mathrm{~nm}$ repre-

measurements on the polymeric film containing the micelles to better understand about these properties. Figure 4 shows maps of mechanical properties on the film containing the micelles. In Fig. 4a it is possible to see the map of the elastic properties of the micelle. It is observed that the central region of the micelle, in which the drug is found, has Young's Modulus values higher than the rest of the film. In Fig. $4 \mathrm{~b}$ we see the energy dissipation map due to the viscous forces on the same region of the film. Again, in the region of the film where the micelles are located, it is possible to observe higher dissipation values.

The viscoelastic properties of micelles are important issues for drug release, permanence and stability in blood flow. Nivaggioli and co-authors [58] report that the release

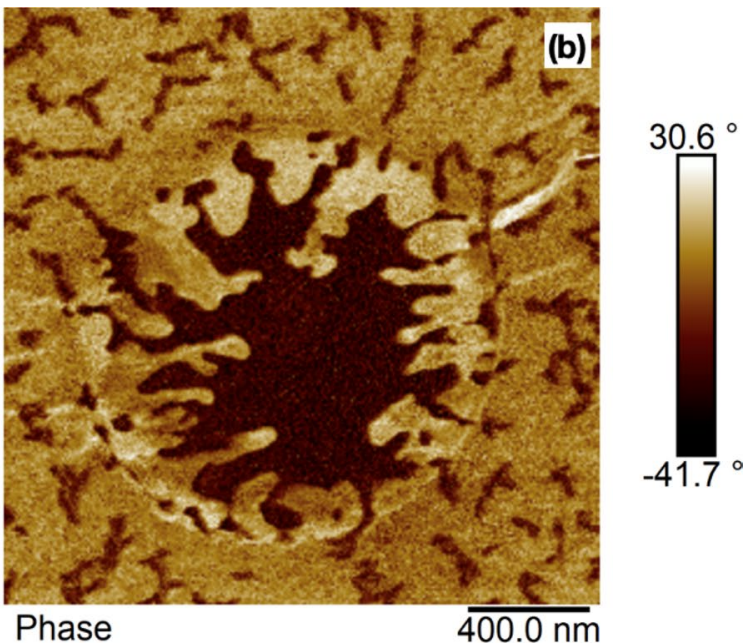

sented in the figure by the red dotted bar. b Phase image of a micelle showing two distinct phases in the micelle, related to the drug's inclusion by the polymer

depends on the local friction on the micelle imposed by the environment.

To better understand quantitatively the nanorheology of polymeric films containing micelles, we used the atomic force microscope as a nanoindenter, varying the indentation speed to observe the viscoelastic behavior of the film.

The average values of Young's Modulus $(E)$ and energy dissipation are both shown in Fig. 5. We have changed the vertical scan frequencies to investigate the response of the polymeric films containing micelles with varying indentation speeds: $2 \mathrm{kHz}, 1 \mathrm{kHz}, 0.5 \mathrm{kHz}$ and $0.25 \mathrm{kHz}$. The reason why $E$ increases while Dissipation (due the viscous forces) decreases with the indentation speed can be explained in terms of the Deborah's number (De) [59] that characterizes
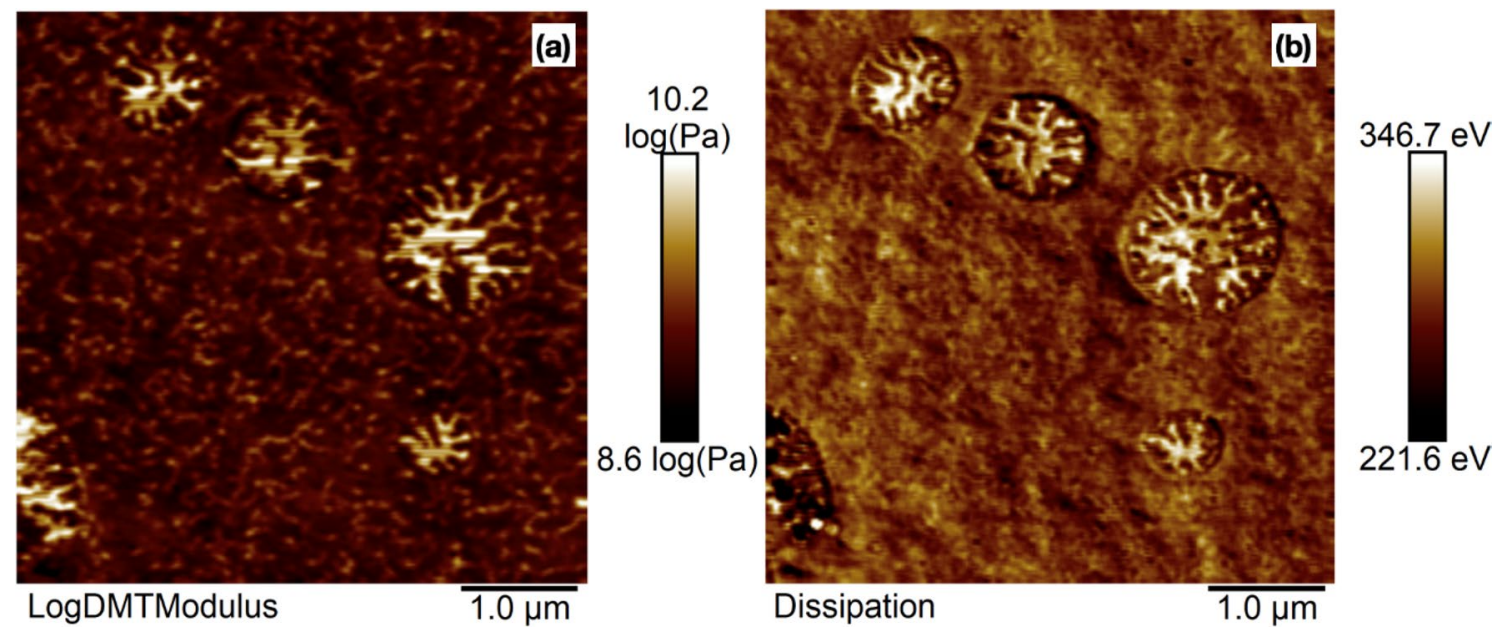

Fig. 4 a AFM Young's modulus map and $\mathbf{b}$ energy dissipation map of Hydroxychloroquine/azithromycin polymeric nanomicelles emulsion 
A)

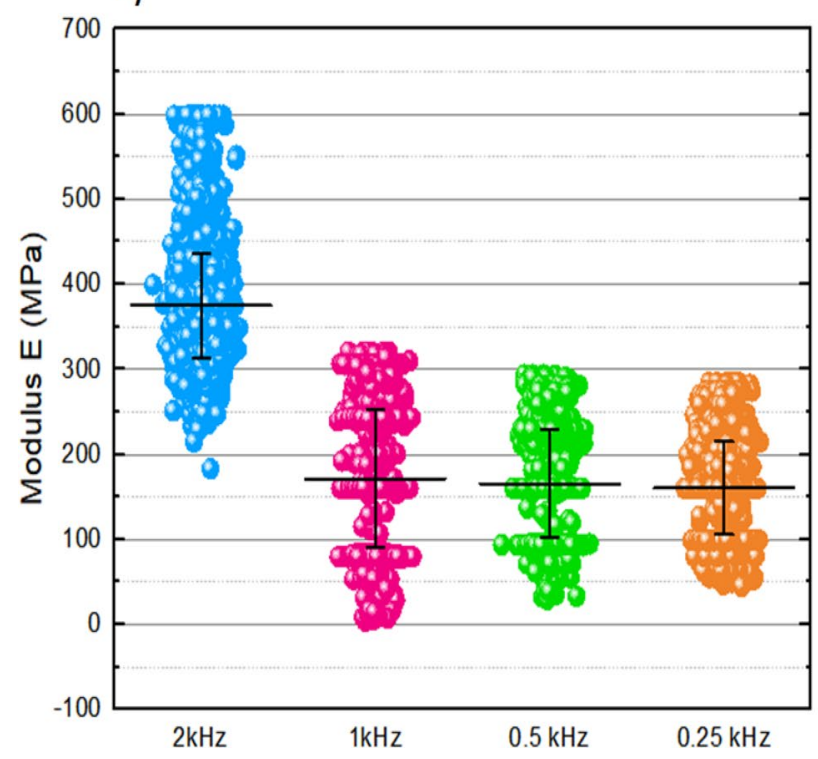

Fig. 5 A) Scattering graph of Young's modulus (MPa) values of the film of nanomicelles submitted to different acquisition frequencies of AFM force curves $(2 ; 1 ; 0.5$ and $0.25 \mathrm{kHz})$. The horizontal bars represent the mean value of $E(\mathrm{MPa})$ for each frequency, respectively: 374.7 MPa (2 kHz), 171.3 MPa (1 kHz), 165.2 MPa (0.5 kHz) and $160.4 \mathrm{MPa}(0.25 \mathrm{kHz})$. The vertical bars represent the standard deviation. B) Scattering plot of energy dissipation values of the film of

the fluidity of a material under specific flow conditions. Deborah's number is defined by the ratio between the time of stress relaxation and the characteristic time of the experiment duration. Deborah's number increases with an increase in frequency.

The polymeric solution containing micelles, in blood flow, will be subject to a low flow rate with a long relaxation time, having a fluid-like behavior. This solution will be subject to processes such as blood pumping, diffusion in capillary vessels, until it reaches the cells where the drug is to be delivered. Such processes take a relatively long time (reaching hours). We see in Fig. 5 that at low frequencies (long relaxation times and low De values), the polymeric film containing micelles behaves as fluid-like, helping with diffusion and dissemination characteristics.

\section{Raman spectroscopy}

The Raman spectroscopy (Fig. 6) has been performed in the nanomicelle sample to identify the encapsulation and the presence of each component in the nano-formulation. Is possible to observe in the spectra specific peaks corresponding to each component of the formulation.

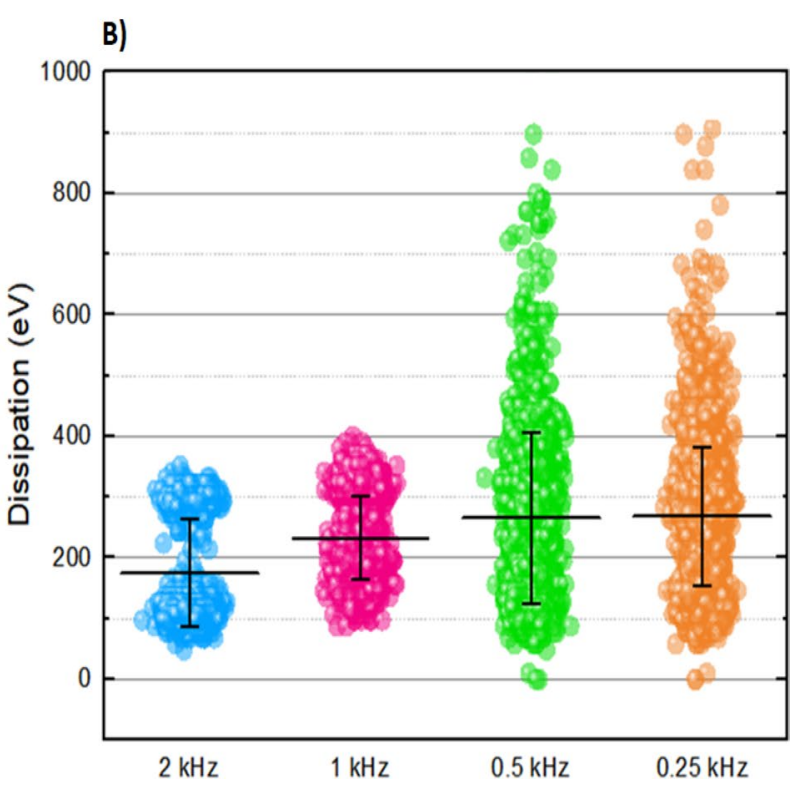

nanomicelles submitted to different acquisition frequencies of AFM force curves $(2 ; 1 ; 0.5$ and $0.25 \mathrm{kHz})$. The horizontal bars represent the mean value of dissipation $(\mathrm{eV})$ for each frequency, respectively: $173.6 \mathrm{eV}(2 \mathrm{kHz}), 232.9 \mathrm{eV}(1 \mathrm{kHz}), 263.8 \mathrm{eV}(0.5 \mathrm{kHz})$ and $267.1 \mathrm{eV}(0.25 \mathrm{kHz})$. The vertical bars represent the standard deviation

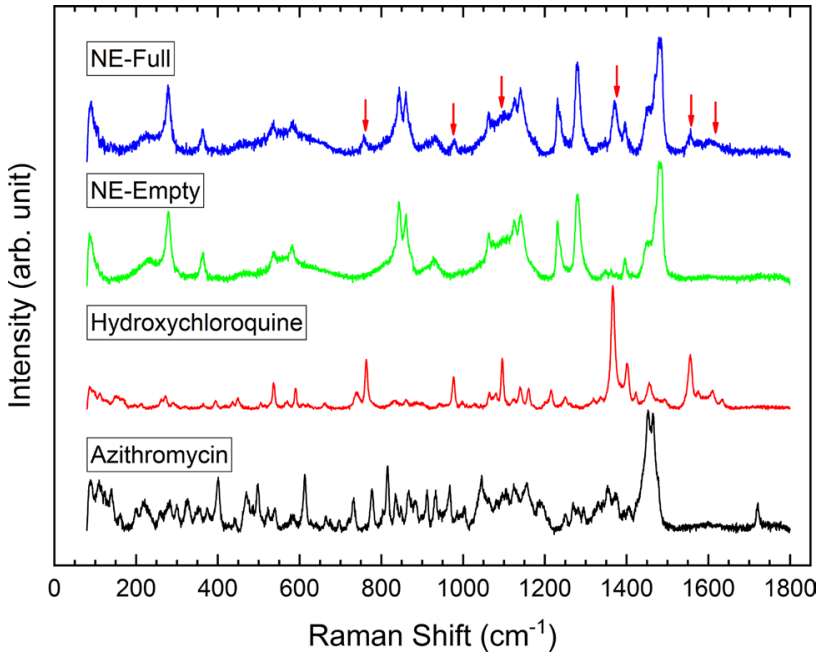

Fig. 6 Raman spectroscopy performed on nanomicelles (NE) showing the presence of both compounds: hydroxychloroquine and azithromycin

\section{Average size determination by dynamic light scattering and zeta potential: polymeric nanoparticle}

The average diameter of the hydroxychloroquine nanoparticle showed a mean size of $390 \mathrm{~nm}$ (Fig. 7) with a PDI 


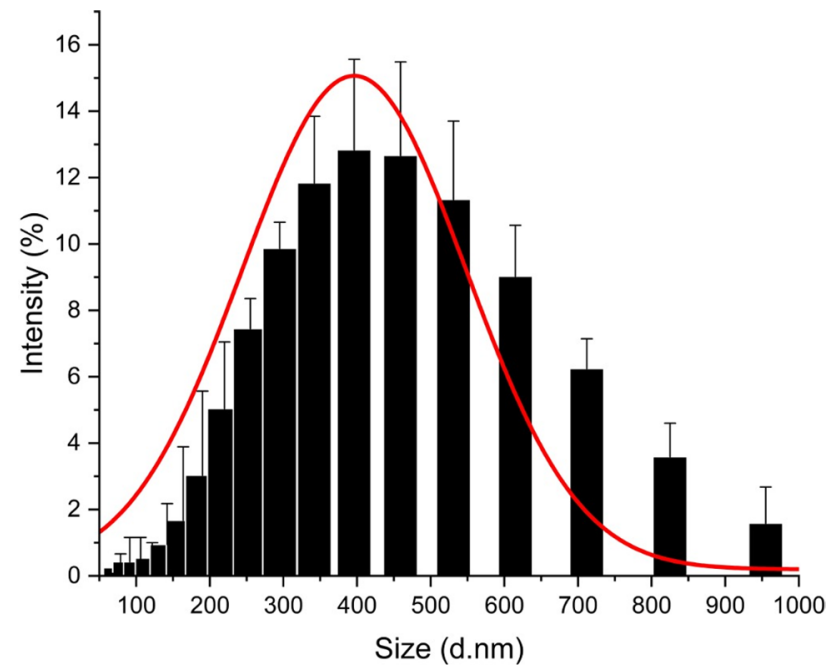

Fig. 7 Dynamic light scattering (DLS) analysis of the polymeric PLA/PVA/hydroxychloroquine/azithromycin nanosystem
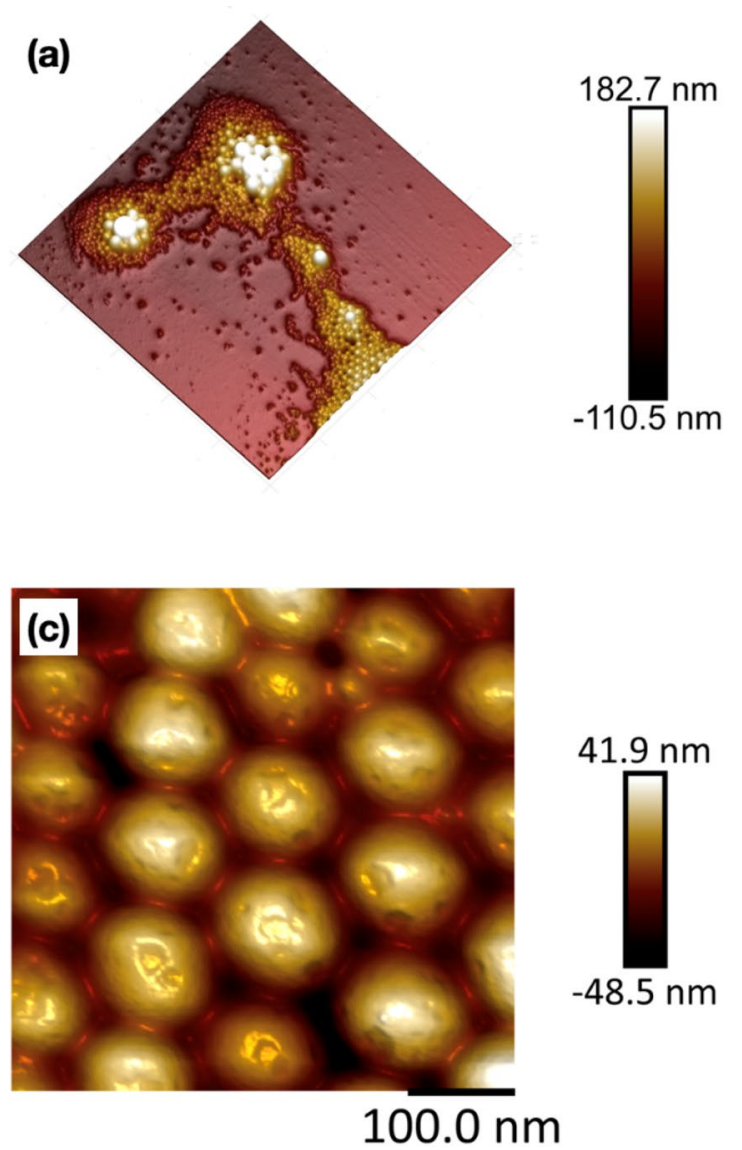

Fig. 8 a Three-dimensional AFM image of the PVA/PLA/Hydroxychloroquine/Azithromycin nanoparticles solution film with lateral scanning of $5 \mu \mathrm{m}$. b Height image of the NPs. The green dashed line corresponds to the region of the cross section shown in the detail. The value of 0.256 corroborating the monodispersive behavior. The zeta potential analysis showed a mean zeta potential of $-3.3 \mathrm{mV}$, with a conductivity of $0.049 \mathrm{~S} / \mathrm{cm}$ and electrophoretic mobility of $-0.2576 \mu \mathrm{m} . \mathrm{cm} / \mathrm{V} . \mathrm{s}$

\section{Atomic force microscopy: polymeric nanoparticle}

The AFM images of the PLA/PVA/hydroxychloroquine/ azithromycin nanoparticles corroborate the DLS results, as shown in the images in Fig. 8. The nanoparticles have a very uniform structure and size. The adhesion map shows adhesive forces of the order of piconewtons, with different adhesion sites on the surface, probably due to the blending of PLA/PVA polymers.

\section{Proliferation assay}

To evaluate the effect of hydroxychloroquine and azithromycin loaded nanosystems on the cell viability, we performed the MTT assay testing the doses of $25 \mu \mathrm{g} / \mathrm{mL}$, $50 \mu \mathrm{g} / \mathrm{mL}$ and $100 \mu \mathrm{g} / \mathrm{mL}$. MTT readout is a measure of
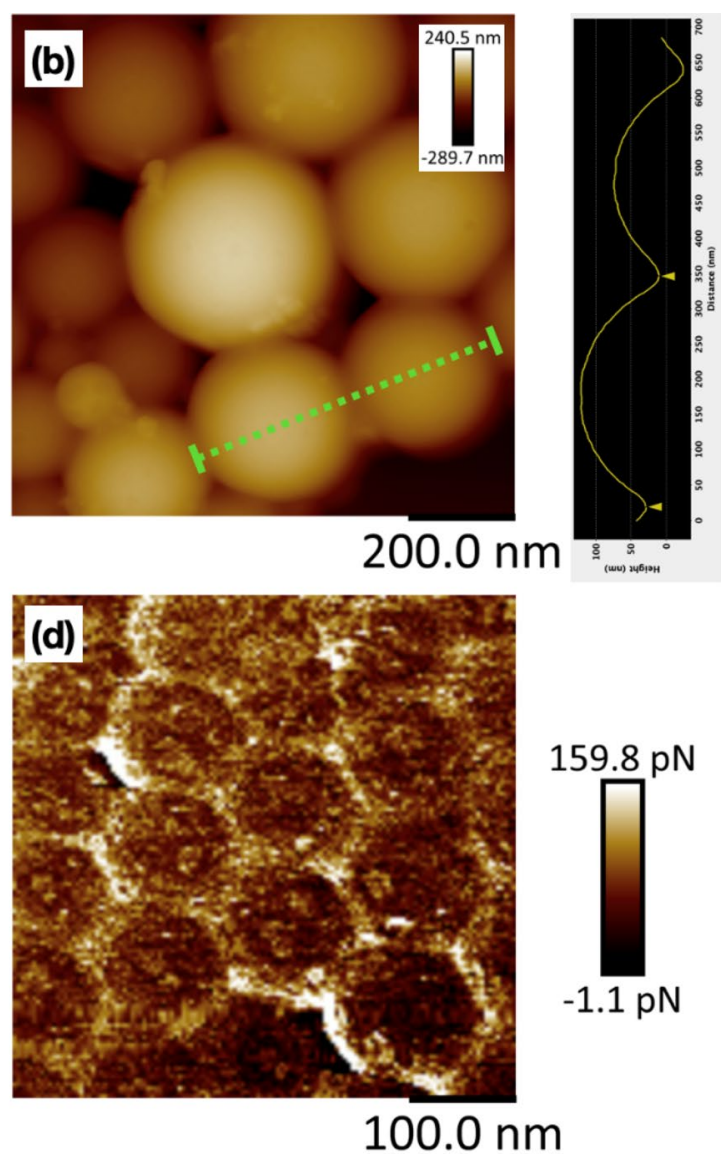

diameter between the arrows of the profile is $334 \mathrm{~nm}$. c AFM image of the NPs showing their uniform profile and chain arrangement and d corresponding adhesion map 
Fig. 9 Effects of Hydroxychloroquine and azithromycin loaded Nanosystems on cellular viability. FGH cells were incubated with $25 \mu \mathrm{g} / \mathrm{mL}, 50 \mu \mathrm{g} / \mathrm{mL}$ and $100 \mu \mathrm{g} / \mathrm{mL}$ of Hydroxychloroquine and azithromycin non-encapsulated, nanomicelle or nanoparticle for $24 \mathrm{~h}$. Cytotoxicity was evaluated using the 3-(4,5-dimethylthiazol2yl)-2,5-diphenyltetrazolium bromide MTT assay

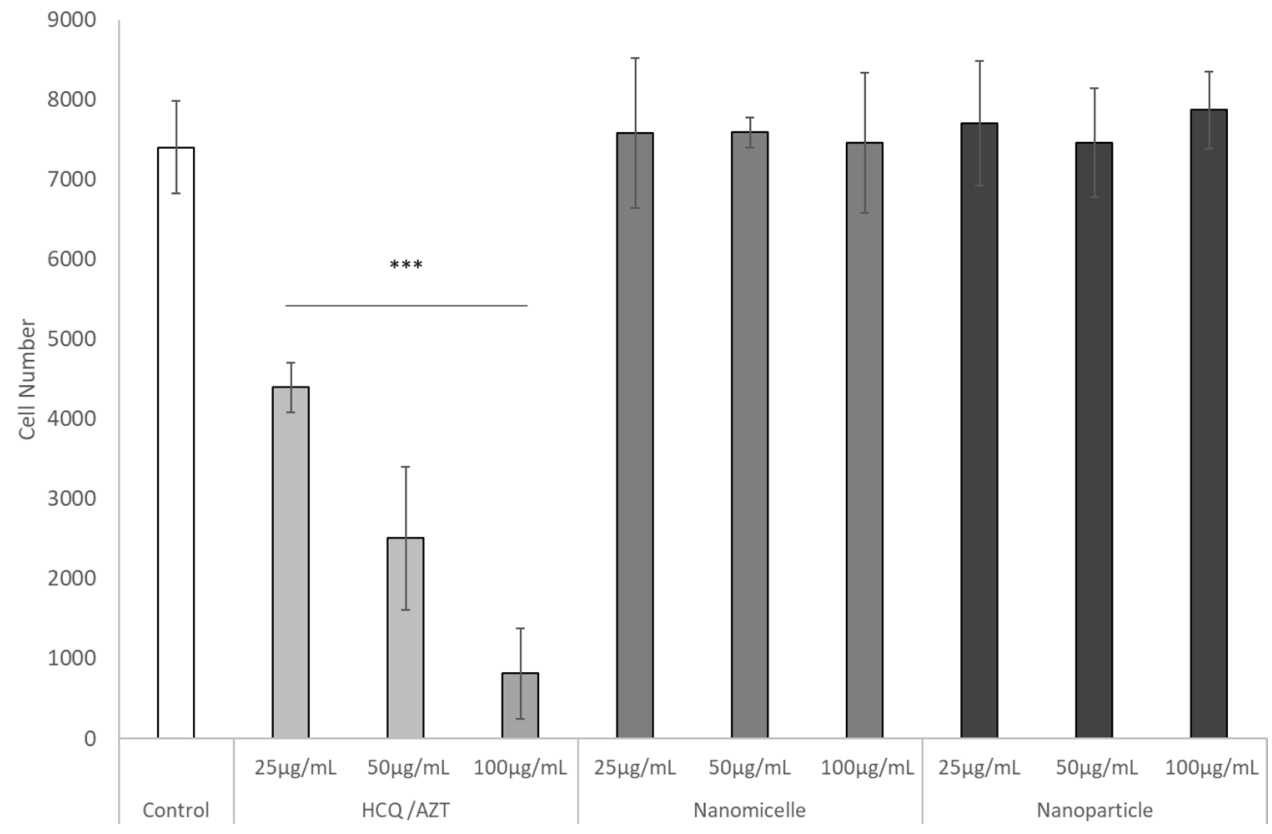

total metabolic activity in a cell culture. The data presented in Fig. 9 revealed dose-dependent cytotoxicity of hydroxychloroquine and azithromycin non-encapsulated. However, the cell viability in all concentration of the nanosystems wasn't significantly different than untreated control, indicating that both nanoparticles and nanomicelles loaded with hydroxychloroquine and azithromycin had no toxic effects in FGH cells.

\section{Wound-healing assay}

Even in the absence of cytotoxicity, nanoparticles may physically interact with cells and slow down their movement in a nonspecific manner, which leads to the question of whether wound healing can be impeded without a reduction in cell viability [54]. To have a better understanding about the effects of hydroxychloroquine and azithromycin loaded nanosystems on physiology cellular, we treated FGH cells with $25 \mu \mathrm{g} / \mathrm{mL}, 50 \mu \mathrm{g} / \mathrm{mL}$ and $100 \mu \mathrm{g} / \mathrm{mL}$ of Nanoparticle and Nanomicelle loaded with hydroxychloroquine and azithromycin or with hydroxychloroquine and azithromycin non-encapsulated for $24 \mathrm{~h}$ and analyzed cell migration comparing with positive control $(10 \% \mathrm{FBS})$. The results are expressed in Fig. 10. We found that migration capacity of cell was significantly decreased by hydroxychloroquine and azithromycin non-encapsulated. At the concentration of $100 \mu \mathrm{g} / \mathrm{mL} \mathrm{HCQ}$, the wound size at $24 \mathrm{~h}$ was bigger than the wound size at $0 \mathrm{~h}$. In part, this can be explained by the high cytotoxicity of hydroxychloroquine and azithromycin non-encapsulated at this concentration. We also observed that both nanosystems were unable to change the migration on FGH cells.

\section{Pulmonary application: in vivo tissue deposition}

The both nanodrugs were successfully labeled (>99\%) with Tc-99 m. In both cases, no visual formation of crystal or change in color has been observed. The efficacy showed by the RTLC corroborates the quality of the direct radiolabeling process (see Tables 1, 2).

The tissue deposition of nanomicelle (Fig. 11) showed that most of the nanosystem after intratracheal instillation was uptaken by the lungs and kept there for $24 \mathrm{~h}$. Is also possible to observe an uptake by stomach and small intestine in the period of $2 \mathrm{~h}$. In the case of the nanoparticle (Fig. 12) is possible to observe a consistent uptake by the lungs at $2 \mathrm{~h}$, $4 \mathrm{~h}$ and $24 \mathrm{~h}$. A discrete uptake id observed in stomach and large intestine.

\section{Antiviral efficacy}

To evaluate whether the nanosystems present antiviral effect, we evaluate their ability to inhibit SARS-CoV-2 in vitro infection and reduce RNA copy numbers in culture supernatants. We observed that treatment with both nanosystems and also HCQ/AZT using concentrations ranging from 12.5 to $100 \mu \mathrm{g} / \mathrm{mL}$ successfully inhibited viral infection and RNA copy numbers (Fig. 13). To further explore the antiviral potential of the nanosystems, we treated Vero E6 cells with concentrations ranging from 0.781 to $3.125 \mu \mathrm{g} /$ mL. Analysis of viral RNA copy numbers by quantitative real-time PCR revealed that, at the lowest concentration $(0.781 \mu \mathrm{g} / \mathrm{mL})$, nanomicelle significantly reduced the viral load when compared to nanoparticle or HCQ/AZT (Fig. 13). Furthermore, when the concentration of $3.125 \mu \mathrm{g} / \mathrm{mL}$ was 
(A)

Oh
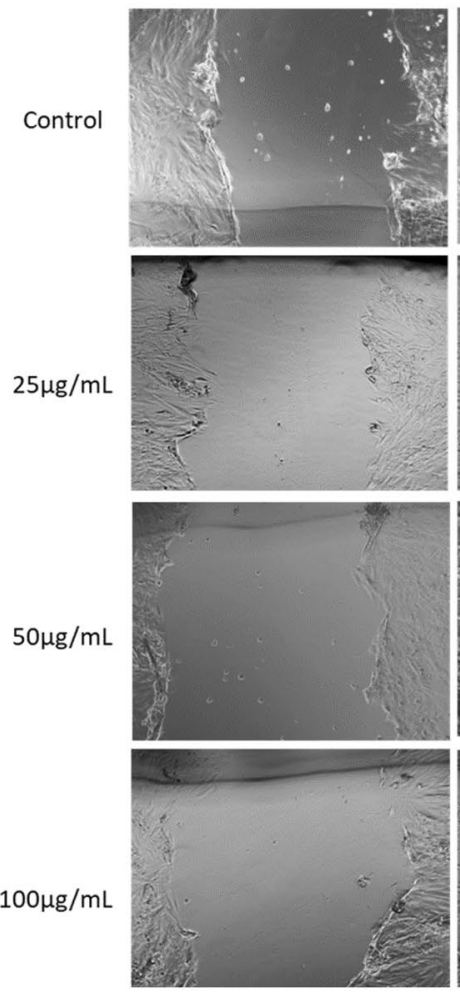

(B)
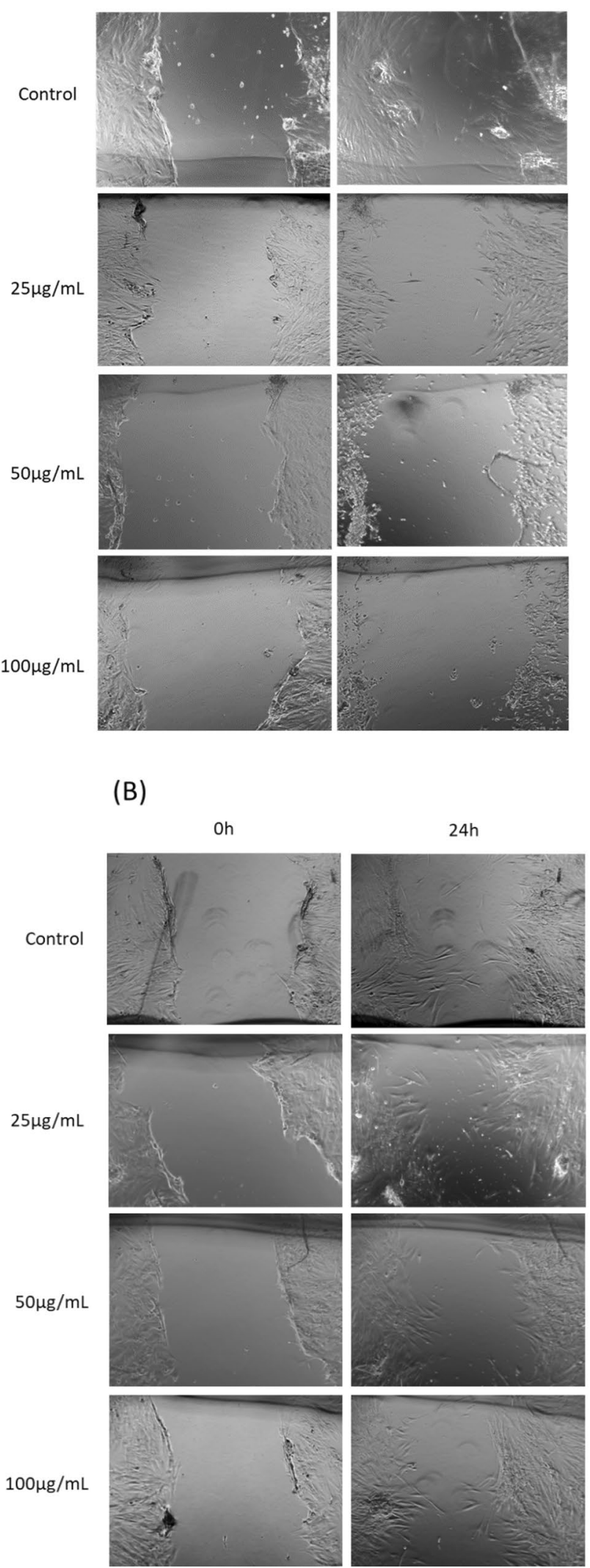

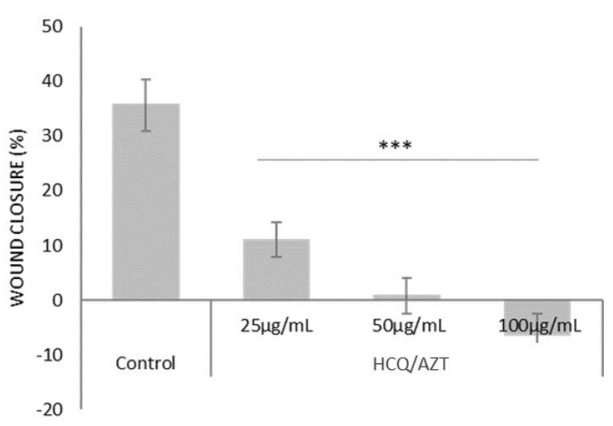

$100 \mu \mathrm{g} / \mathrm{mL}$

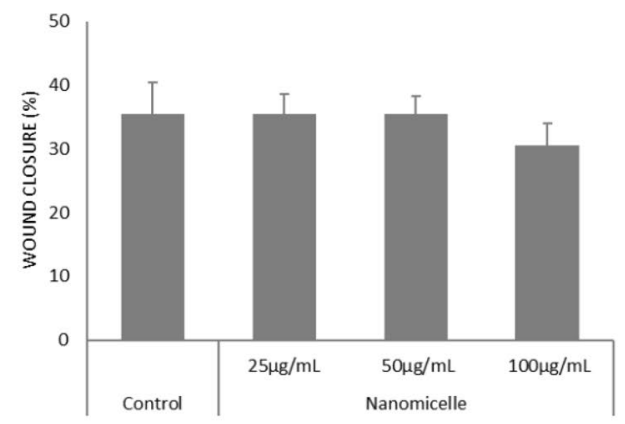

$100 \mu \mathrm{g} / \mathrm{mL}$ of hydroxychloroquine and azithromycin drugs (A) or nanomicelles (B) and nanoparticles $(\mathbf{C})$ loaded with hydroxychloroquine and azithromycin- Mean e standard variation were calculated from 3 individual experiments $(* p<0.05)$
Fig. 10 Effects of hydroxychloroquine (HCQ) and azithromycin (AZT) loaded Nanosystems in human fibroblasts migration. Cells were cultured for $24 \mathrm{~h}$ in medium with $10 \%$ FBS (control) or in the presence of $25 \mu \mathrm{g} / \mathrm{mL}, 50 \mu \mathrm{g} / \mathrm{mL}$ and 
(C)

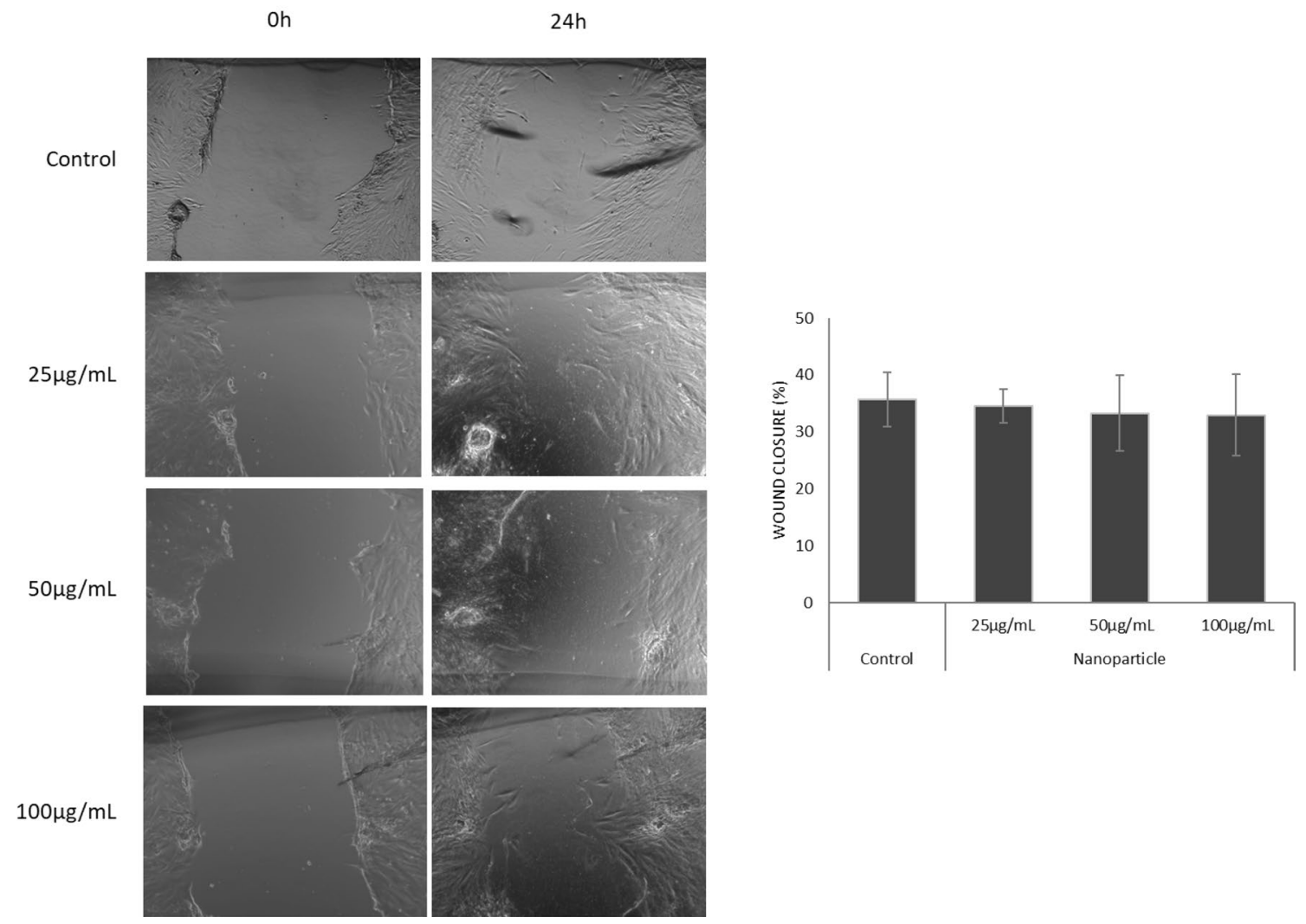

Fig. 10 (continued)

Table 1 Radiochemical purity (\%) of ${ }^{99 \mathrm{~m}} \mathrm{Tc}$ - PLA/ PVA/hydroxychloroquine/ azithromycin in $2 \mathrm{~h}, 4 \mathrm{~h}$ and $24 \mathrm{~h}$

Table 2 Radiochemical purity (\%) of ${ }^{99 \mathrm{~m}} \mathrm{Tc}$ hydroxychloroquine/ azithromycin nanomicelle in $2 \mathrm{~h}, 4 \mathrm{~h}$ and $24 \mathrm{~h}$

\begin{tabular}{ll}
\hline Time (Hour) & $\begin{array}{l}\text { Radiochemi- } \\
\text { cal purity } \\
(\%)\end{array}$ \\
\hline 2 & $99.66 \pm 0.31$ \\
4 & $99.72 \pm 0.52$ \\
24 & $99.46 \pm 0.18$ \\
\hline
\end{tabular}

\begin{tabular}{ll}
\hline Time (Hour) & $\begin{array}{l}\text { Radiochemi- } \\
\text { cal purity } \\
(\%)\end{array}$ \\
\hline 2 & $99.90 \pm 0.22$ \\
4 & $99.88 \pm 0.12$ \\
24 & $99.65 \pm 0.11$ \\
\hline
\end{tabular}

used for comparison, only treatment with nanomicelle led to undetectable levels of SARS-CoV-2 RNA copies. In summary, when using nanomicelle we observed an important decrease in viral copy numbers following a dose-dependent effect from approximately $10^{8}$ at the untreated condition to approximately $10^{2}$ at the $0.781 \mu \mathrm{g} / \mathrm{ml}$ drug concentration to a

complete viral suppression at the concentration of $3.125 \mu \mathrm{g} /$ $\mathrm{ml}$. It is important to note that neither nanosystems nor HCQ/AZT presented significant cytotoxicity using the tested concentrations (Fig. 14).

Thus, these results clearly demonstrate that, at lower concentrations, nanomicelle effectively controls SARS-CoV-2 replication.

\section{Discussion}

In recent publication, Danaei et al. [60] demonstrated that a dispersion with polydispersity index (PDI) value varying from 0.1 to 0.5 , for pharmaceutical products, may be considered a monodisperse system. Also, according to Han and Jiang a PDI value higher than 0.1 but lower than 0.3 , can be defined as monodispersive [61]. In this work, we were more careful and considered that dispersions with PDI value higher than 0.3 are considered non-monodispersed systems. In a very conservative analysis and focusing on a pharmaceutical product, the nanomicelle with PDI of 0.348 exhibits non-monodispersive behavior which mean that the size variation is too high. This can be partially explained by the fact that wormlike nanomicelles are elongated flexible 
Fig. 11 Tissue deposition of nanomicelle containing ${ }^{99 \mathrm{~m}}$ Tc-hydroxychloroquine / azithromycin in healthy male Wistar rats at $2 \mathrm{~h}, 4 \mathrm{~h}$ and $24 \mathrm{~h}$ post-injection period

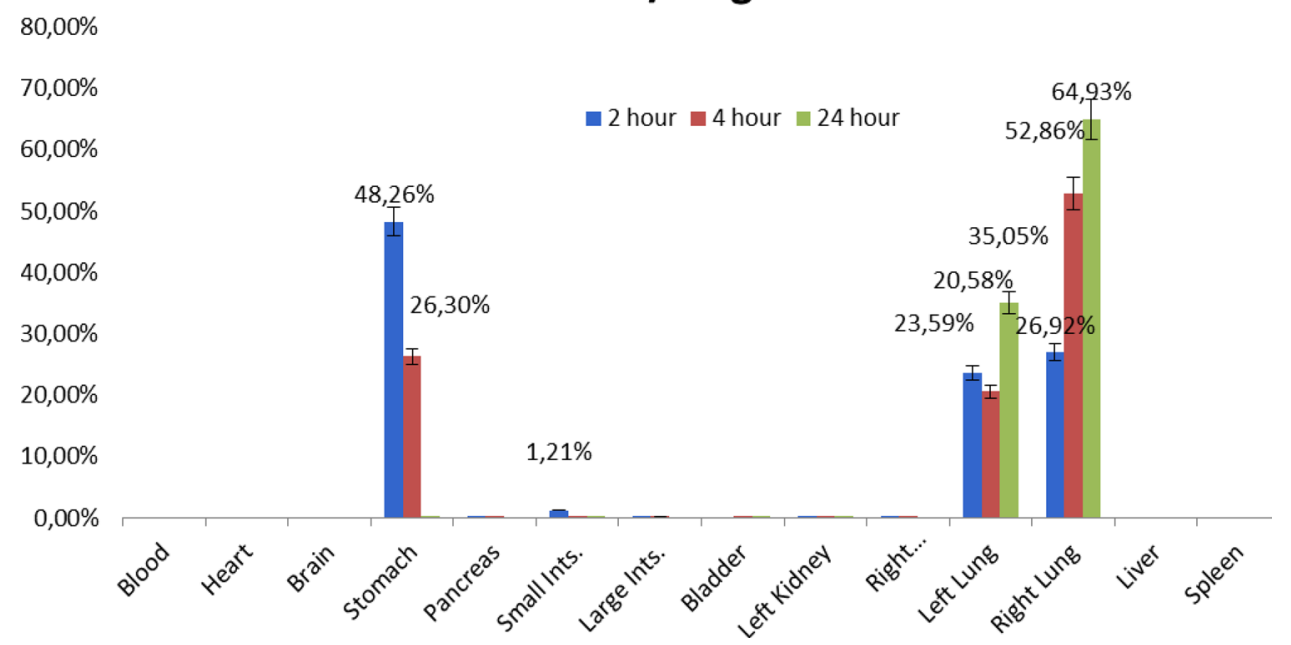

self-assembly structures able to entangle into a dynamic network forming an intricate structure, which may influence the size and the PDI analysis [62]. Thus, the quality of the nanomicelles dispersion is not fine and the system behavior non-monodispersed. The nanoparticles have a PDI of 0.256 , value below 0.3 . Thus, we will assume that value of 0.348 will not influence in the monodispersive behavior of the nanomicelle. On the other hand, the polydispersity index (PDI) from the nanoparticle (0.256) was undoubtedly monodispersive.

Regarding the zeta potential a great difference has been observed. The nanomicelles showed almost no charge, with a zeta potential of $0.1 \mathrm{mV}$ while the nanoparticle showed a negative charge of $-3.3 \mathrm{mV}$. According to Frohlich [63] the charge is essential for the nanosystem penetration. Positively charged nanosystems seems to have a facilitate traffic into the cell while negatively charged nanosystem shows a more difficult cell-trafficking. However, is also reported that positively charged nanosystem shows a higher toxicity effect on the cell. At this point, no further assay has been done to better understanding the influence of charge in the cell uptake of both nanosystems, especially in host cells with the virus, which could have the machinery and morphology changed by the virus proliferation and any additional comment would be merely speculative.

Regarding the shape, is well known that spherical nanoparticles are readily internalized nanosystems [64, 65]. Regarding micelles nanosystems the information about cell internalization is still contradictory [41]. However, a study performed by Geng et al.[66] demonstrated that nanomicelles are also internalized. According to Gupta et al. [67] nanomaterial may cross the cells membranes in microseconds, corroborating the fact that both nanosystem are faster internalized.
In the case of nanomicelles used in this study, is possible to observe in the AFM image that due the high agglomeration formation may lead to a nanosystem with an overall size about $602 \mathrm{~nm}$ as demonstrated by the DLS and the AFM image. The Raman spectroscopy demonstrated the presence of all components in the nanomicelle formed. According to De Barros et al. [68] Raman spectroscopy in a useful tool for identification of components in a nanosystem. The size of $602 \mathrm{~nm}$ associated with the shape, also improves the cell internalization of this nanosystem by the cell increasing the therapeutic effect on the virus, which has been confirmed by the Fig. 13. Regarding the difference on the efficacy observed when comparing the two nanosystem, we believe that a pronounced burst effect [69] of nanomicelles may have caused the difference. We also believe that with a higher exposition time of Vero cells infected with Sars-Cov-2 to nanoparticles the effect could be the same.

The purpose to study the effect of both nanosystems on FGH cells (human gingival fibroblast) in both cell viability as wound-healing assay was to determine the biocompatibility as any toxicity. The chosen of FGH was based in two factors: i) they are among the most abundant resident cells from the oral mucosa, and ii) they have a higher ability for scarless wound healing when compared to skin fibroblasts [70, 71].

The results of both proliferation assay demonstrated that regardless the difference between the two nanosystems used, both were harmless for FGH, corroborating the initial safety aspect evaluated. While the hydroxychloroquine and azithromycin drug has been shown cytotoxic, the nanosystems (nanomicelle or nanoparticle) were incapable to interfere in the proliferation of the FGH cells, even in high doses. The same was observed in the wound-healing assay, non-encapsulated hydroxychloroquine and azithromycin 


\section{\% Dose / Organ}

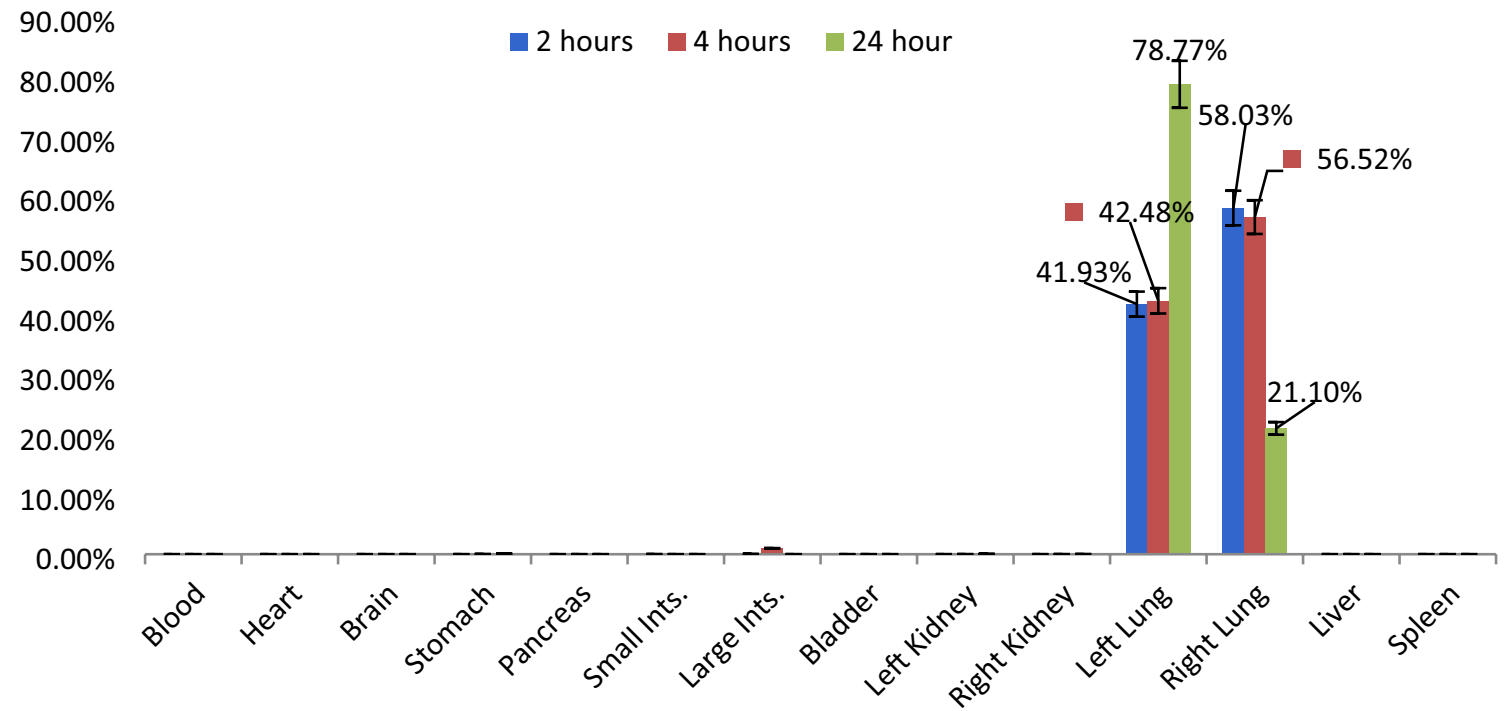

Fig. 12 Tissue deposition of nanopaticle containing ${ }^{99 \mathrm{~m}}$ Tc-PLA/PVA/hydroxychloroquine/azithromycin in healthy male Wistar rats at $2 \mathrm{~h}, 4 \mathrm{~h}$ and $24 \mathrm{~h}$ post-injection period

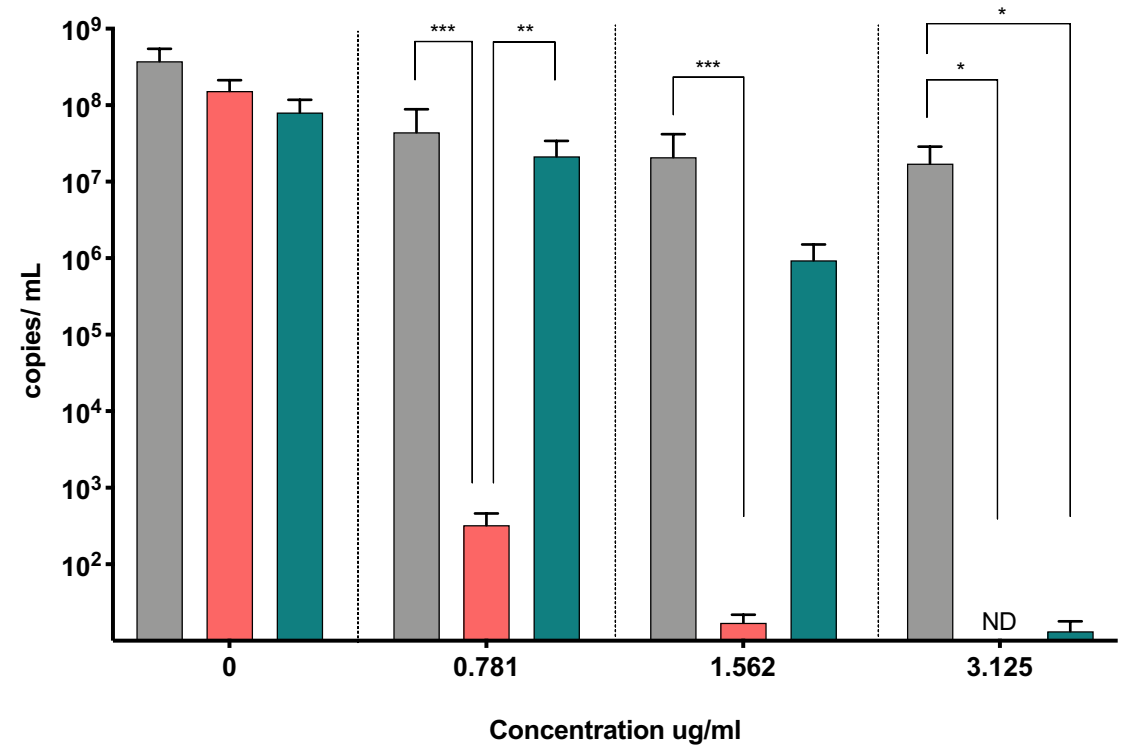

$\square$ Nanoparticle HCQ/AZT

$\square$ HCQ/AZT

Fig. 13 Effects of hydroxychloroquine (HCQ) and azithromycin (AZT) loaded nanosystems on SARS-CoV-2 in vitro infection of Vero E6 cells. Cells were treated for $1 \mathrm{~h}$ with nanomicelles (salmon), nanoparticles (gray), the combination of HCQ/AZT (green) with different concentrations as indicated in the $x$ axis or maintained with culture medium only (Untreated-0). After, cells were infected with SARS-CoV-2 in a MOI of 0.05 and incubated for $2 \mathrm{~h}$. Then,

significantly decreased the migration of FGH cells at all concentrations tested. However, both nanoparticles loaded with Hydroxychloroquine and azithromycin were not able to interfere in the migratory capacity of these cells. The use of infected cells were washed and treated again as indicated or remained untreated. After $48 \mathrm{~h}$, viral RNA in culture supernatants was determined by RT-qPCR using specific primers and probe against SARS-CoV-2 Rdrp gene. Data are mean \pm SEM of two independent experiments. Data were analyzed by two-way ANOVA followed by Tukey's multiple comparison test, where $* p<0.05 ; * * p<0.001$ and $* * * p<0.0005$

FGH cells for the assessment of safety of nanoparticles has been described previously. According to Helal-Neto et al. [54] nanoparticles that cannot cause severe damage to FGH cells can be considered secure for use. This is corroborated 
Fig. 14 Cytotoxicity of hydroxychloroquine (HCQ) and azithromycin (AZT) loaded Nanosystems in Vero E6 cells. The cytotoxicity was determined by LDH assay. Vero E6 cells were treated for $48 \mathrm{~h}$ with different concentrations of nanomicelles (salmon), nanoparticles (gray), the combination of HCQ/AZT (green) or maintained with culture medium only (Untreated-0). Then, the supernatants were collected and the amount of LDH was quantified. After Data are mean \pm SEM of two independent experiments

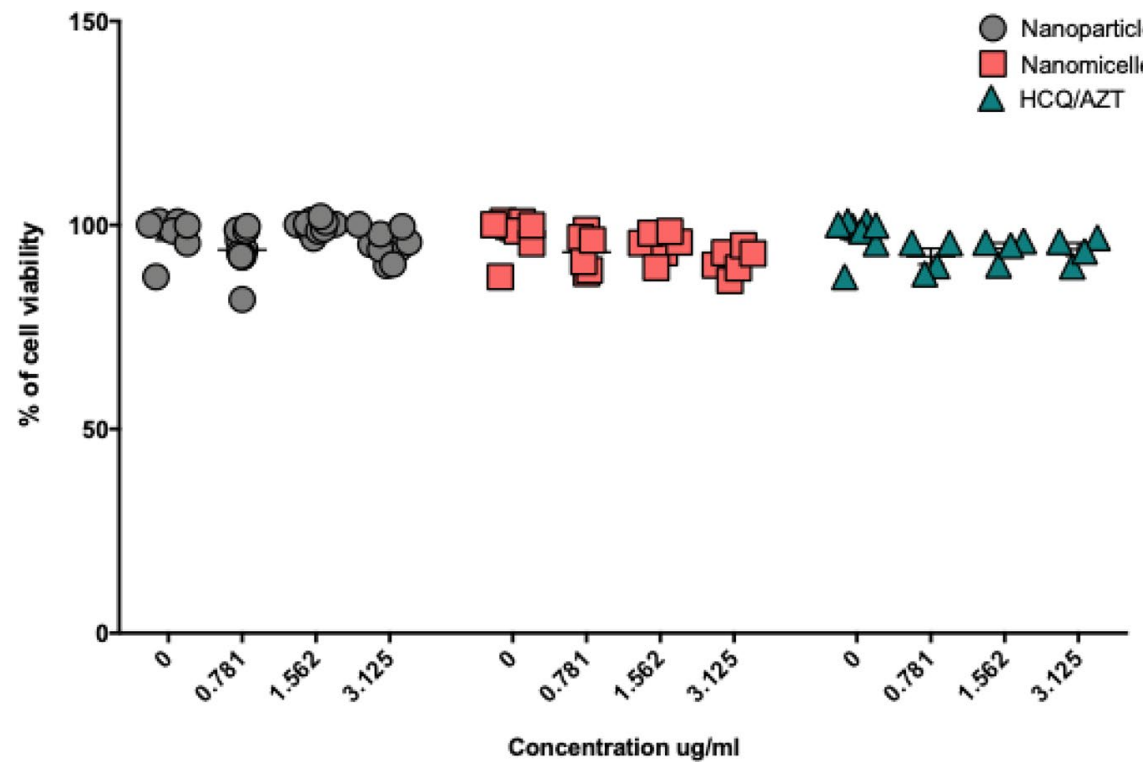

by Assis et al. [72] that using Ag nanoparticles/ $\alpha-\mathrm{Ag} 2 \mathrm{WO} 4$ demonstrated that they are safe for use after assay with FGH cells. Also, Silva de Barros et al. [73] demonstrated that capped mesoporous silica with hydroxyapatite is secure after evaluation with FGH cells.

The radiolabeling with ${ }^{99 \mathrm{~m}} \mathrm{Tc}$ by the direct via showed to be efficient and very useful. Also, the data showed that both nanosystems are very stable in a period of $24 \mathrm{hs}$, probably due the main mechanisms involved in this process: the chemisorption and the physisorption of ${ }^{99 \mathrm{~m}} \mathrm{Tc}$ on the nanosystem $[74,75]$. This data corroborates the use of this technique for tracking nanoparticles in many circumstances.

Regarding the tissue deposition after intratracheal instillation is possible to observe that both nanosystems were able to reach the lungs and remain there for a period of $24 \mathrm{~h}$. The amount of nanomicelle in stomach and small intestine in the period of $2 \mathrm{~h}$ and $4 \mathrm{~h}$ is probably due a fraction of the nanomicelle, which must have been swallowed during the instillation or remained in the GI tract and was finally swallowed. The tissue deposition $24 \mathrm{~h}$ post intratracheal instillation is very similar to Woods et al. [76] which have measured the tissue deposition ( $24 \mathrm{~h}$ post pulmonary application) of albumin-nanoparticles radiolabeled with 111In (111 Indium) and found small amounts in kidneys and intestine, which they claimed to be cleared from the lungs both by translocation across the lung mucosal barrier, as well as mucociliary clearance.

The pulmonary route represents an important via for the treatment of various pulmonary and systemic diseases [76]. In the case of nanoparticulate drugs, offers the potential for local application with an efficient transport. Nonetheless, pulmonary delivery of nanodrugs allows optimum therapeutic concentrations as the lung is capable of absorbing pharmaceuticals either for local deposition or for systemic delivery $[77,78]$.
Regarding the size, according to Ryting et al. [79] and Chow et al. [80], nanosystems with a size smaller than $150 \mathrm{~nm}$ are reported to have delayed lung clearance, increased protein interactions and more transepithelial transport compared to larger particles. According to Paranjpe and Muller-Goymann [81] nanoparticles between 1 and $0.5 \mu \mathrm{m}$ are deposited in the alveolar region. Finally, according to Lim et al. [82] nanoparticle between 30 and $500 \mathrm{~nm}$ can be more permeable to thick mucus layer presented in lung. Thus, the size of $390 \mathrm{~nm}$ and $602 \mathrm{~nm}$ nanoparticle and nanomicelle, respectively, seems to be good choices for pulmonary application.

The use of inhalation route for the delivery of drug directly to the lungs is well known and used in several diseases, such as asthma, chronic obstructive pulmonary disease (COPD), cystic fibrosis and pneumonia [83-85]. Recently, Tai et al. [86] have developed a nebulized isotonic hydroxychloroquine aerosol to improve the efficacy of the treatment of COVID-19. According to their findings they were able to increase the lung dose concentration from 20 to $100 \mathrm{mg} / \mathrm{mL}$. In this regard, the results observed in tissue deposition using radiolabeled nanosystems with ${ }^{99 \mathrm{~m}} \mathrm{Tc}$, administered by intratracheal instillation in healthy animals represented an important possibility to pulmonary application as route for the treatment of SARS-CoV-2, acting direct in the lungs and allowing the systematic treatment as reducing the systemic adverse effect.

The use of nanosystem for the treatment of SARS-CoV-2 has been demonstrated previously [86-88]. According to Elia et al. [89] is possible to deliver specific vaccine based on lipid nanoparticles (LNPs)-encapsulated SARS-CoV-2 human Fcconjugated receptor-binding domain (RBD-hFc) with good results. Additionally, Khaiboullina et al. [90] have developed a TiO2 (TNPs) for virus deactivation. The antiviral effect 
showed that nanomicelle, although neutrally charged, was more efficient than the nanoparticle (negatively charged) to reduce viral replication. In terms of dose-response, nanomicelle showed a dose-response effect, with lower doses showing higher efficacy than nanoparticle or HCQ + AZT. This must be faced as advantage since lower doses are required, especially for reducing the adverse effects. In the specific case, considering that HCQ may show severe adverse reactions in higher doses [91] the data suggesting efficacy in lower doses may represent an important finding.

Regarding the effect of azithromycin and the interface on the nanosystems with in vitro assay, the literature state that azithromycin may act as adjuvant [92] associated with viral load reduction/disappearance in COVID-19 patients. Our data demonstrated that a synergic effect is observed and the especially in nanomicelles the reduction of viral replication is pronounced in very low doses $(0.781 \mu \mathrm{g} / \mathrm{mL})$.

\section{Conclusion}

The study demonstrated that nanosystems may be used for the treatment of SARS-CoV-2 infection. The results demonstrated that nanomicelles of hydroxychloroquine co-loaded with azithromycin were capable to reduce the viral replication efficiently.

Our data also demonstrated that the nanomicelles are more efficient than nanoparticles against the SARS-CoV-2, probably due the burst effect and a better cell penetration.

The pulmonary direct application demonstrated that both nanoparticles were capable to reach the inner parts of the lungs and remained there for a long time ( $>4 \mathrm{~h}$ ), which may represent a primary route of application of these nanosystems.

Finally, our data demonstrate that polymeric nanosystems containing hydroxychloroquine and azithromycin have antiviral characteristics and do not show cytotoxicity in in vitro assay. Thus, these nanoparticles could be a safety alternative for the treatment of COVID-19, especially for pulmonary application.

Supplementary Information The online version contains supplementary material available at https://doi.org/10.1007/s40097-022-00476-3.

Acknowledgements This study was funded by Carlos Chagas Filho Foundation for Research Support of Rio de Janeiro State (FAPERJ) (E-26/201.946/2020, E-26/200.815/2021 and 26/010.000981/2019) and CNPq (301069/2018-2) to Ralph Santos-Oliveira.

\section{References}

1. Tang, Q., Song, Y., Shi, M., Cheng, Y., Zhang, W., Xia, X.-Q.: Inferring the hosts of coronavirus using dual statistical models based on nucleotide composition. Sci. Rep. 5, 327-345 (2015)
2. Poon, L.L.M., Peiris, M.: Emergence of a novel human coronavirus threatening human health. Nat. Med. 3, 317-319 (2020)

3. Hu, B., Guo, H., Zhou, P., Shi, Z.L.: Characteristics of SARSCoV-2 and COVID-19. Nat Rev Microbiol. 3, 141-154 (2021)

4. Cardoso-Lima, R., Souza, P.F.N., Guedes, M.I.F., Santos-Oliveira, R., Rebelo Alencar, L.M.: SARS-CoV-2 unrevealed: ultrastructural and nanomechanical analysis. Langmuir 36, 10762-10769 (2021)

5. Dong, E., Du, H., Gardner, L.: An interactive web-based dashboard to track COVID-19 in real time. Lancet Infect. Dis. 20, 533-534 (2020)

6. Huang, C., Wang, Y., Li, X., Ren, L., Zhao, J., Hu, Yi., Zhang, Li., Fan, G., Xu, J., Gu, X.: Clinical features of patients infected with 2019 novel coronavirus in Wuhan, China. Lancet 395, 497-506 (2020)

7. Wang, D., Hu, Bo., Hu, C., Zhu, F., Liu, X., Zhang, J., Wang, B., Xiang, H., Cheng, Z., Xiong, Y.: Clinical characteristics of 138 hospitalized patients with 2019 Novel Coronavirus-Infected Pneumonia in Wuhan, China. JAMA 323, 1061-1075 (2020)

8. Guan, Wj., Ni, Z.-Y., Hu, Y., Liang, W.-H., Ou, C.-G., He, J.-X., Liu, L., Shan, H., Lei, C.-L., Hui, D.S.C.: Clinical Characteristics of Coronavirus Disease 2019 in China. N. Engl. J. Med. 382, 1708-1720 (2020)

9. Nalbandian, A., Sehgal, K., Gupta, A., Madhavan, M.V., McGroder, C., Stevens, J.S., Cook, J.R., Nordvig, A.S., Shalev, D., Sehrawat, T.S., Ahluwalia, N., Bikdeli, B., Dietz, D., DerNigoghossian, C., Liyanage-Don, N., Rosner, G.F., Bernstein, E.J., Mohan, S., Beckley, A.A., Seres, D.S., Choueiri, T.K., Uriel, N., Ausiello, J.C., Accili, D., Freedberg, D.E., Baldwin, M., Schwartz, A., Brodie, D., Garcia, C.K., Elkind, M.S.V., Connors, J.M., Bilezikian, J.P., Landry, D.W., Wan, E.Y.: Post-acute COVID-19 syndrome. Nat Med. 27, 601-615 (2021)

10. Bakhiet, M., Taurin, S.: SARS-CoV-2: Targeted managements and vaccine development. Cytokine Growth Factor Rev. 58, 16-29 (2021)

11. Shi, Y., Wang, Y., Shao, C., Huang, J., Gan, J., Huang, X., Bucci, E., Piacentini, M., Ippolito, G., Melino, G.: COVID-19 infection: the perspectives on immune responses: the perspectives on immune responses. Cell Death Differ. 27, 1451-1454 (2020)

12. Xu, Z., Shi, L., Wang, Y., Zhang, J., Huang, L., Zhang, C., Liu, S., Zhao, P., Liu, H., Zhu, Li.: Pathological findings of covid-19 associated with acute respiratory distress syndrome. Lancet Respir Med. 8, 420-422 (2020)

13. Chan, J.F.-W., Yuan, S., Kok, K.-H., To, K.K.-W., Chu, H., Yang, J., Xing, F., Liu, J., Yip, C.C.-Y., Poon, R.W.S.: A familial cluster of pneumonia associated with the 2019 novel coronavirus indicating person-to-person transmission: a study of a family cluster: a study of a family cluster. Lancet 395, 514-523 (2020)

14. Zhou, F., Yu, T., Du, R., Fan, G., Liu, Y., Liu, Z., Xiang, J., Wang, Y., Song, B., Gu, X.: Clinical course and risk factors for mortality of adult inpatients with COVID-19 in Wuhan, China: a retrospective cohort study: a retrospective cohort study. Lancet $\mathbf{3 9 5}$, 1054-1062 (2020)

15. Gao, J., Tian, Z., Yang, X.: Breakthrough: chloroquine phosphate has shown apparent efficacy in treatment of covid-19 associated pneumonia in clinical studies.: Chloroquine phosphate has shown apparent efficacy in treatment of COVID-19 associated pneumonia in clinical studies. Biosci Trends. 14, 72-73 (2020)

16. Wang, Y., Zhang, D., Du, G., Du, R., Zhao, J., Jin, Y., Fu, S., Gao, L., Cheng, Z., Lu, Q.: Remdesivir in adults with severe COVID19: a randomised, double-blind, placebo-controlled, multicentre trial: a randomised, double-blind, placebo-controlled, multicentre trial. Lancet 5, 300-314 (2020)

17. Gautret, P., Lagier, J.-C., Parola, P., Hoang van, T., Meddeb, L., Mailhe, M., Doudier, B., Courjon, J., Giordanengo, V., Vieira, V.E.: Hydroxychloroquine and azithromycin as a treatment of 
COVID-19: results of an open-label non-randomized clinical trial: results of an open-label non-randomized clinical trial. Int J Antimicrob Agents. 56, 105949-105969 (2020)

18. Mcchesney, E.W.: Animal toxicity and pharmacokinetics of hydroxychloroquine sulfate. Am J Med 75, 11-18 (1983)

19. Yao, X., Ye, F., Zhang, M., Cui, C., Huang, B., Niu, P., Liu, X., Zhao, L., Dong, E., Song, C., Zhan, S., Lu, R., Li, H., Tan, W., Liu, D.: In vitro antiviral activity and projection of optimized dosing design of hydroxychloroquine for the treatment of severe acute respiratory syndrome coronavirus 2 (SARS-CoV-2). Clin Infect Dis. 71, 732-739 (2020)

20. Ou, T., Mou, H., Zhang, L., Ojha, A., Choe, H., Farzan, M.: Hydroxychloroquine-mediated inhibition of SARS-CoV-2 entry is attenuated by TMPRSS2. PLoS Pathog. 17, e1009212 (2021)

21. Retallack, H., Lullo, E.D., Arias, C., Knopp, K.A., Laurie, M.T., SandovaL-Espinosa, C., Leon, W.R., Mancia, K.R., Ullian, E.M., Spatazza, J.: Zika virus cell tropism in the developing human brain and inhibition by azithromycin. Proc Natl Acad Sci U S A 113, 14408-14413 (2016)

22. Bosseboeuf, E., Aubry, M., Nhan, T., Pina, J.J.D., Rolain, J.M., Raoult, D., Musso, D.: Azithromycin inhibits the replication of Zika Virus. J Antivir Antiretrovir. 103, 20-328 (2018)

23. Madrid, P.B., Panchal, R.G., Warren, T.K., Shurtleff, A.C., Endsley, A.N., Green, C.E., Kolokoltsov, A., Davey, R., Manger, I.D., Gilfillan, L.: Evaluation of Ebola virus inhibitors for drug repurposing. Acs Infect Dis. 1, 317-326 (2015)

24. Bacharier, L.B., Guilbert, T.W., Mauger, S.T., Boehmer, S., Beigelman, A., Fitzpatrick, A.M., Jackson, D.J., Baxi, S.N., Benson, M., Burnham, C.D.: Early administration of azithromycin and prevention of severe lower respiratory tract illnesses in preschool children with a history of such illnesses. JAMA 314, 2034-2046 (2015)

25. Khezri, M.R., Zolbanin, N.M., Ghasemnejad-Berenji, M., Jafari, R.: Azithromycin: immunomodulatory and antiviral properties for SARS-CoV-2 infection. Eur J Pharmacol. 905, 174191 (2021)

26. Echeverría-Esnal, D., Martin-Ontiyuelo, C., Navarrete-Rouco, M.E., De-Antonio Cuscó, M., Ferrández, O., Horcajada, J.P., Grau, S.: Azithromycin in the treatment of COVID-19: a review. Expert Rev Anti Infect Ther. 19, 147-163 (2021)

27. Arshad, S., Kilgore, P., Chaudhry, Z.S., Jacobsen, G., Wang, D.D., Huitsing, K., Brar, I., Alangaden, G.J., Ramesh, M.S., McKinnon, J.E., O’Neill, W., Zervos, M., Henry, F.: Treatment with hydroxychloroquine, azithromycin, and combination in patients hospitalized with COVID-19. Int J Infect Dis. 97, 396-403 (2020)

28. Singh, L., Kruger, H.G., Maguire, G.E.M., Govender, T., Parboosing, R.: The role of nanotechnology in the treatment of viral infections. Ther Adv Infect Dis. 4, 105-131 (2017)

29. Mosafer, J., Sabbaghi, A.-H., Badiee, A., Dehghan, S., Tafaghodi, M.: Preparation, characterization and in vivo evaluation of alginate-coated chitosan and trimethylchitosan nanoparticles loaded with PR8 influenza virus for nasal immunization. Asian J Pharm Sci. 14, 216-221 (2019)

30. Rossnerova, A., Honkova, K., Pelclova, D., Zdimal, V., Hubacek, J.A., Chvojkova, I., Vrbova, K., Rossner, P., Topinka, J., Vlckova, S.: DNA methylation profiles in a group of workers occupationally exposed to nanoparticles. Int. J. Mol. Sci. 21, 2420-2430 (2020)

31. Mello, F.V.C., de Moraes, G.N., Maia, R.C., Kyeremateng, J., Iram, S.H., Santos-Oliveira, R.: The effect of nanosystems on ATP-binding cassette transporters: understanding the influence of nanosystems on multidrug resistance protein-1 and P-glycoprotein. Int. J. Mol. Sci. 21, 2630-2640 (2020)

32. Colino, C.I., Lanao, J.M., Gutierrez-Millan, C.: Targeting of hepatic macrophages by therapeutic nanoparticles. Front. Immunol. 11, 327-345 (2020)

33. Florczak, A., Mackiewicz, A., Dams-Kozlowska, H.: Cellular uptake, intracellular distribution and degradation of
Her2-targeting silk nanospheres. Int. J. Nanomed. 14, 6855-6865 (2019)

34. Majumder, J., Minko, T.: Recent developments on therapeutic and diagnostic approaches for COVID-19. AAPS J. 23, 14 (2021)

35. Ashraf, M.A., Peng, W., Zare, Y., Rhee, Y.P.: Effects of size and aggregation/agglomeration of nanoparticles on the interfacial/ interphase properties and tensile strength of polymer nanocomposites. Nanosc. Res Lett. 13, 327-337 (2018)

36. Moritz, M., Geszke-Moritz, M.: Recent developments in application of polymeric nanoparticles as drug carriers. Adv Clin Exp Med. 24, 749-758 (2015)

37. - Yadav, H.K.S, Almokdad, A.A., Shaluf, S.I.M., Debe, M.S.: Polymer-based nanomaterials for drug-delivery carriers. Nanocarr. For Drug Deliv.ery (2019).

38. Liu, Y., Yang, G., Baby, T., Tengjisi, C., Dong, W., David, A., Zhao, C.X.: Stable polymer nanoparticles with exceptionally high drug loading by sequential nanoprecipitation. Angew. Chem. Int. Ed. 59, 4720-4728 (2020)

39. Rani, R., Dilbaghi, N., Dhingra, D., Kumar, S.: Optimization and evaluation of bioactive drug-loaded polymeric nanoparticles for drug delivery. Int. J. Biol. Macromol. 78, 173-179 (2015)

40. Juneja, R., Roy, I.: Surface modified PMMA nanoparticles with tunable drug release and cellular uptake. Rsc Adv. 4, 4447244479 (2014)

41. Martin, H.J., White, B.T., Scanlon, C.J., Saito, T., Dadmun, M.D.: Tunable synthetic control of soft polymeric nanoparticle morphology. Soft Matter 13, 8849-8857 (2017)

42. Nelemans, L.C., Gurevich, L.: Drug delivery with polymeric nanocarriers-cellular uptake mechanisms. Materials (Basel). 13, 366-386 (2020)

43. Fornaguera, C., Castells-Sala, C., Borrós, S.: Unraveling polymeric nanoparticles cell uptake pathways: two decades working to understand nanoparticles journey to improve gene therapy: two decades working to understand nanoparticles journey to improve gene therapy. Adv Exp Med Biol. 5, 327-345 (2019)

44. Teixeira, M.C., Carbone, C., Sousa, M.C., Espina, M., Garcia, M.L., Sanchez-Lopez, E., Souto, E.B.: Nanomedicines for the delivery of antimicrobial peptides (AMPs). Nanomaterials (Basel). 10, 560-582 (2020)

45. Osminkina, L.A., Agafilushkina, S.N., Kropotkina, E.A., Saushkin, N.Y., Bozhev, I.V., Abramchuk, S.S., Samsonova, J.V., Gambaryan, A.S.: Antiviral adsorption activity of porous silicon nanoparticles against different pathogenic human viruses. Bioact Mater. 7, 39-46 (2022)

46. Rivera-Hernández, G., Antunes-Ricardo, M., Martínez-Morales, P., Sánchez, M.L.: Polyvinyl alcohol based-drug delivery systems for cancer treatment. Int J Pharm. 600, 120478 (2021)

47. Essa, S., Louhichi, F., Raymond, M., Hildgen, P.: Improved antifungal activity of itraconazole-loaded PEG/PLA nanoparticles. J. Microencapsul. 30, 205-217 (2012)

48. Singh, A., Roopkishora, S., Pradeep, G., Ramji, M., Nita, K., Sokindra, K.M.: Development and validation of UV-spectrophotometric method for the estimation of hydroxychloroquine sulphate. Indian J Chem Technol. 23, 237-239 (2016)

49. Ferraz, L.R.M., Santos, F.L.A., Ferreira, P.A., Maia-Junior, R.T.L., Rosa, T.A., Costa, S.P.M., Melo, C.M., Rolim, L.A., Rolim-Neto, P.J.: quality by design in the development and validation of analytical method by ultraviolet-visible spectrophotometry for quantification of Hydroxychloroquine Sulfate. Int J Pharm Sci Res. 8, 4666-4676 (2015)

50. Bhimani, S., Sanghvi, G., Pethani, T., Dave, G., Airao, V., Sharma, T., Sheth, N., Vaishnav, D.: Development of the UV spectrophotometric method of azithromycin in API and stress degradation studies. Int. Lett. Chem. Phys. Astron. 68, 48-53 (2016) 
51. Jayanna, B.K., Nagendrappa, G., Arunkumar, G.N.: Spectrophotometric estimation of azithromycin in tablets. Indian J. Pharm. Sci. 74, 365-372 (2012)

52. Bakheit, A.H.H., Al-Hadiya, B.M.H., Abd-Elgalil, A.A.: Azithromycin profiles of drug substances. Excip. Relat. Methodol. 1, 40 (2014)

53. Derjaguin, B., Muller, V., Toporov, Y.: Effect of contact deformations on the adhesion of particles. J. Colloid Interface Sci. 53, 314-326 (1975)

54. Helal-Neto, E., Barros de, A.O.D.S., Saldanha-Gama, R., Brandão-Costa, R., Alencar, L.M.R., Santos dos, C.C., Martínez-Máñez, R., Ricci-Junior, E., Alexis, F., Morandi, V., Barja-Fidalgo, C., Santos-Oliveira, R.: Molecular and cellular risk assessment of healthy human cells and cancer human cells exposed to nanoparticles. Int. J. Mol. Sci. 21, 230-252 (2019)

55. -Centers for Disease Control and Prevention, Respiratory Viruses Branch, Division of Viral Diseases. Real-Time RT-PCR Panel for Detection 2019-Novel Coronavirus. (CDC/NCIRD/DVD, 2020).

56. de Jesus, F.C., Helal-Neto, E., Portilho, F.L., et al.: Effect of obesity on biodistribution of nanoparticles. J Control Release. 281, 11-18 (2018)

57. Haspeslagh, E., Debeuf, N., Hammad, H., Lambrecht, B.N.: murine models of allergic asthma. Methods Mol Biol. 1559, 121-136 (2017)

58. Nivaggioli, T., Tsao, B., Alexandridis, P., Hatton, T.A.: Microviscosity in pluronic and tetronic poly(ethylene oxide)Poly(propylene oxide) block copolymer micelles. Langmuir 11, 119-126 (1995)

59. Poole, R.J.: The Deborah and Weissenberg numbers. Br. Soc. Rheol. Rheol. Bull. 53, 32-39 (2012)

60. Danaei, M., Dehghankhold, M., Ataei, S., Davarani, F.H., Javanmard, R., Dokhani, A., Khorasani, S., Mozafari, M.: Impact of particle size and polydispersity index on the clinical applications of lipidic nanocarrier systems. Pharmaceutics. 10, 57-72 (2018)

61. Jiang X, Bai C, Liu M (eds) (2019) Nanotechnology and microfluidics

62. Dreiss, C.A.: Wormlike micelles: where do we stand? recent developments, linear rheology and scattering techniques.: where do we stand? Recent developments, linear rheology and scattering techniques. Soft Matter 3, 956-776 (2007)

63. Fröhlich, E.: The role of surface charge in cellular uptake and cytotoxicity of medical nanoparticles. Int. J. Nanomed. 2, 5577$5592(2012)$

64. Wang, W., Gaus, K., Tilley, R., Gooding, J.J.: The impact of nanoparticle shape on cellular internalisation and transport: what do the different analysis methods tell us. Mater. Horiz. 6, 1538-1547 (2019)

65. Chen, L., Xiao, S., Zhu, H., Wang, L., Liang, H.: Shape-dependent internalization kinetics of nanoparticles by membranes. Soft Matter 12, 2632-2641 (2016)

66. Geng, Y., Dalhaime, R.P., Cai, S., TsaI, R., Tewari, M., Minko, T., Discher, D.E.: Shape effects of filaments versus spherical particles in flow and drug delivery. Nat. Nanotechnol. 2, 249-255 (2007)

67. Gupta, R., Badhe, Y., Mitragotri, S., Rai, B.: Permeation of nanoparticles across the intestinal lipid membrane: dependence on shape and surface chemistry studied through molecular simulations. Nanoscale 12, 6318-6333 (2020)

68. da Silva de Barros, A.O., Portilho, F.L., Dos Santos Matos, A.P., Ricci-Junior, E., Alencar, L.M.R., Dos Santos, C.C., Paumgartten, F.J.R., Iram, S.H., Mazier, D., Franetich, J.F., Alexis, F., SantosOliveira, R.: Preliminary studies on drug delivery of polymeric primaquine microparticles using the liver high uptake effect based on size of particles to improve malaria treatment. Mater. Sci. Eng. C Mater. Biol. Appl. 128, 1275 (2021)
69. Bhattacharjee, S.: Understanding the burst release phenomenon: toward designing effective nanoparticulate drug-delivery systems. Ther. Deliv. 12, 21-36 (2020)

70. Mah, W., Jiang, G., Olver, D., Cheung, G., Kim, B., Larjava, H., Häkkinen, L.: Human gingival fibroblasts display a non-fibrotic phenotype distinct from skin fibroblasts in three-dimensional cultures. PLoS ONE 9, e90715 (2014)

71. Soares, A.S.L.A., Scelza, S.M.Z., Spoladore, J., Gallito, M.A., Oliveira, F., Moraes, R.C.M., Alves, G.G.: Comparison of primary human gingival fibroblasts from an older and a young donor on the evaluation of cytotoxicity of denture adhesives. J. Appl. Oral. Sci. 26, 327-351 (2018)

72. Assis, M., Robeldo, T., Foggi, C.C., et al.: Ag Nanoparticles/ $\alpha-$ $\mathrm{Ag}_{2} \mathrm{WO}_{4}$ composite formed by electron beam and femtosecond irradiation as potent antifungal and antitumor agents. Sci. Rep. 9, 9927 (2019)

73. da Silva de Barros, A.O., Rebêlo Alencar, L.M., Alexis, F., Santos-Oliveira, R.: Distinct methodologies to produce capped mesoporous silica with hydroxyapatite and the influence in intracellular signaling as cytotoxicity on human umbilical vein endothelial cells. Bioengineering 8, 125 (2021)

74. Costa, B., Ilem-Özdemir, D., Santos-Oliveira, R.: Technetium99m metastable radiochemistry for pharmaceutical applications: old chemistry for new products. J. Coord. Chem. 72, 1-26 (2019)

75. Santos-Oliveira, R.: Application of technetium 99 metastable radioactive nanosystems: nanoparticles, liposomes, and nanoemulsion for biomedical application. Curr. Pharmacol. Rep. 5, 281-302 (2019)

76. Woods, A., Patel, A., Spina, D., Riffo-Vasquez, Y., Babin-Morgan, A., de Rosales, R.T.M., Sunassee, K., Clark, S., Collins, H., Bruce, K., Dailey, L.A., Forbes, B.: In vivo biocompatibility, clearance, and biodistribution of albumin vehicles for pulmonary drug delivery. J. Control Release. 210, 1-9 (2015)

77. Sarasija, S., Patil, J.: Pulmonary drug delivery strategies: a concise, systematic review. Lung India 29, 44 (2012)

78. Groneberg, D.A., Fischer, A., Chung, K.F., Daniel, H.: Molecular mechanisms of pulmonary peptidomimetic drug and peptide transport. Am. J. Respir. Cell. Mol. Biol. 30, 251-260 (2004)

79. Rytting, E., Nguyen, J., Wang, X., Kissel, T.: Biodegradable polymeric nanocarriers for pulmonary drug delivery. Expert Opin. Drug. Deliv. 5, 629-639 (2008)

80. Chow, A.H., Tong, H.H., Chattopadhyay, P., Shekunov, B.Y.: Particle engineering for pulmonary drug delivery. Pharm. Res. 24, 411-437 (2007)

81. Paranjpe, M., Müller-Goymann, C.: Nanoparticle-mediated pulmonary drug delivery: a review. Int. J. Mol. Sci. 15, 5852-5873 (2014)

82. Lim, Y.H., Tiemann, K.M., Hunstad, D.A., Elsabahy, M., Wooley, K.L.: Polymeric nanoparticles in development for treatment of pulmonary infectious diseases. Wiley Interdiscip. Rev. Nanomed. Nanobiotechnol. 8, 842-871 (2016)

83. Borghardt, J.M., Kloft, C., Sharma, A.: Inhaled therapy in respiratory disease: the complex interplay of pulmonary kinetic processes. Can. Respir. J. 19, 2732017 (2018)

84. Newman, S.P.: Drug delivery to the lungs: challenges and opportunities. Ther. Deliv. 8, 647-661 (2017)

85. Eedara, B.B., Alabsi, W., Encinas-Basurto, D., Polt, R., Ledford, J.G., Mansour, H.M.: Inhalation delivery for the treatment and prevention of COVID-19 infection. Pharmaceutics. 13, 1077 (2021)

86. Tai, W., Chow, M.Y.T., Chang, R.Y.K., Tang, P., Gonda, I., MacArthur, R.B., Chan, H.-K., Kwok, P.C.L.: Nebulised isotonic hydroxychloroquine aerosols for potential treatment of COVID19. Pharmaceutics. 13, 1260 (2021) 
87. Medhi, R., Srinoi, P., Ngo, N., Tran, H.-V., Randall Lee, T.: Nanoparticle-based strategies to combat COVID-19. ACS Appl. Nano. Mater. 3, 8557-8580 (2020)

88. Dheyab, M.A., Khaniabadi, P.M., Aziz, A.A., Jameel, M.S., Mehrdel, B., Oglat, A.A., Khaleel, H.A.: Focused role of nanoparticles against COVID-19: diagnosis and treatment. Photodiagn. Photodyn. Ther. 34, 102287 (2021)

89. Elia, U., Ramishetti, S., Rosenfeld, R., Dammes, N., Bar-Haim, E., Naidu, G.S., Makdasi, E., Yahalom-Ronen, Y., Tamir, H., Paran, N., Cohen, O., Peer, D.: Design of SARS-CoV-2 hFc-conjugated receptor-binding domain mRNA vaccine delivered via lipid nanoparticles. ACS Nano 15, 9627-9637 (2021)

90. Khaiboullina, S., Uppal, T., Dhabarde, N., Subramanian, V.R., Verma, S.C.: Inactivation of human coronavirus by Titania nanoparticle coatings and UVC radiation: throwing light on SARSCoV-2. Viruses 13, 19 (2020)
91. Jaffe, S.: Regulators split on antimalarials for COVID-19. Lancet 395, 1179-1185 (2020)

92. Butler, C., Dorward, J., Yu, L.-M., Gbinigie, O., Hayward, G., Saville, B., van Hecke, O., Berry, N., Detry, M., Saunders, C., Fitzgerald, M., Harris, V., Patel, M., de Lusignan, S., Ogburn, E., Evans, P., Thomas, N., Hobbs, F.D., Group, PRINCIPLE: Azithromycin for community treatment of suspected COVID-19 in people at increased risk of an adverse clinical course in the UK (PRINCIPLE): a randomised, controlled, open-label, adaptive platform trial. Lancet 397, 1063-1074 (2021)

Publisher's Note Springer Nature remains neutral with regard to jurisdictional claims in published maps and institutional affiliations. 